This item was submitted to Loughborough's Research Repository by the author.

Items in Figshare are protected by copyright, with all rights reserved, unless otherwise indicated.

\title{
Development of a superhydrophobic polyurethane-based coating from a two- step plasma-fluoroalkyl silane treatment
}

PLEASE CITE THE PUBLISHED VERSION

http://dx.doi.org/10.1016/j.ijadhadh.2016.03.007

\section{PUBLISHER}

(C) Elsevier

\section{VERSION}

AM (Accepted Manuscript)

\section{PUBLISHER STATEMENT}

This work is made available according to the conditions of the Creative Commons Attribution-NonCommercialNoDerivatives 4.0 International (CC BY-NC-ND 4.0) licence. Full details of this licence are available at: https://creativecommons.org/licenses/by-nc-nd/4.0/

\section{LICENCE}

CC BY-NC-ND 4.0

\section{REPOSITORY RECORD}

West, James O.F., Gary Critchlow, D.R. Lake, and R. Banks. 2016. "Development of a Superhydrophobic Polyurethane-based Coating from a Two-step Plasma-fluoroalkyl Silane Treatment". Loughborough University. https://hdl.handle.net/2134/22447. 


\title{
Development of a superhydrophobic polyurethane-based coating from a two-
} step plasma-fluoroalkyl silane treatment

\author{
J.O.F.West ${ }^{1}$, G.W.Critchlow ${ }^{1^{*}}$ D.R.Lake ${ }^{1}$ and R.Banks ${ }^{2}$ \\ ${ }^{1}$ Department of Materials, Loughborough University, Loughborough, Leicestershire, \\ LE11 3TU, UK. \\ ${ }^{2}$ Indestructible Paint Co. Ltd, 25 Pentos Drive, Birmingham, B11 3TA, UK. \\ *corresponding author: g.w.critchlow@lboro.ac.uk
}

\begin{abstract}
A method of achieving a superhydrophobic surface based upon a highly filled polyurethane (PU) paint coating has been demonstrated through the use of a combined oxygen/argon plasma pretreatment and a fluoroalkyl silane (FAS) final treatment.
\end{abstract}

The combined plasma-FAS treated PU surface has been investigated and characterised using: field emission gun secondary electron microscope (FEG-SEM); X-ray photoelectron spectroscopy (XPS); energy-dispersive X-ray spectroscopy (EDX); water contact angle analysis (WCA); atomic force microscopy (AFM), and; Fourier transform infrared spectroscopy (FTIR).

It was found that the oxygen/argon plasma treatment increased both the surface roughness $\left(R_{a}\right)$ and surface free energy (SFE) of the $P U$ paint coating from approximately 60 to $320 \mathrm{~nm}$, and, $\sim 52$ to $\sim 80 \mathrm{mN} / \mathrm{m}$ respectively. It was also found that the plasma process created a multiscale roughened texture through the process of differential ablation between the PU polymer and the barium sulphate solid content, which is present in the paint as an extender, and other additives. In addition, the process also imparted favourable polar groups into the PU surface from the ionised and radical oxygen species in the plasma.

When the FAS coating was subsequently applied to the PU without prior plasma treatment, there was a significant increase in water contact angles. This parameter increased from approximately $60^{\circ}$ on untreated PU to around $130^{\circ}$ with FAS applied. 
In this case, the SFE decreased to $\sim 7.5 \mathrm{mN} / \mathrm{m}$ and showed 42.0 at.\% fluorine present as indicated by XPS.

However, subsequently applying the FAS polymer after plasma pretreatment takes advantage of the known synergistic relationship that exists between surface roughness and low surface free energy coatings. The two processes combined to create superhydrophobicity with a surface that exhibited water contact angles up to $153.1^{\circ}$. With this optimised process, the apparent SFE was $0.84 \mathrm{mN} / \mathrm{m}$ with a more highly fluorinated surface present. In this case 47.2 at.\% surface fluorine was observed by XPS.

In addition to changes in SFE, plasma treatment was also observed to alter levels of surface gloss and colour. After exposure to 600 seconds of plasma gloss levels are shown to reduce from values of $\sim 50$ to $\sim 21(\mathrm{GU})$, with small but significant corresponding increases in the lightness and yellowness of the surface.

Keywords: Superhydrophobicity, polyurethane coatings, plasma treatment, fluoroalkyl silane, surface free energy

\section{Introduction}

Polyurethane (PU) coatings are well-established, being widely employed and studied due to their range of industrially-useful properties [1], [2]. Of particular relevance to the current study, PU coatings find use in automotive exterior applications [3], [4] often as a two component clear coat system [5]. One property of PU coatings that has been the subject of several studies is surface wettability; a number of such studies have focused on increasing the surface wettability [6]-[8] , whilst others have focussed on how to decrease this parameter in order to achieve ultrahydrophobic or superhydrophobic surfaces [9]. In this paper we will regard ultrahydrophobic and superhydrophobic surfaces as those achieving greater than $120^{\circ}$ and $150^{\circ}$ water contact angles (WCA) respectively. The latter will usually also exhibit low contact angle hysteresis, facilitating the ease with which water rolls off the superhydrophobic surface [10]. Importantly, the present study will focus on the attainment of these anti-wetting surface characteristics on PU coatings. PU coatings are, however, inherently relatively hydrophilic. In the present study, the surface physical and 
chemical properties of a PU coating will be modified by increasing roughness and by surface fluorination to achieve this.

Many investigations into ultrahydrophobic and superhydrophobic surfaces have studied, drawn inspiration from, or directly attempted to replicate the lotus leaf with its self-cleaning properties [11]-[13]. The lotus leaf, which has been shown to provide a superhydrophobic surface with a WCA of approximately $165^{\circ}$ [14], has been revealed to work by combining micro-scale papillae and attached nano-scale hairs to achieve multi-scale roughness [13] combined with a "wax-like" chemistry. This combination of physical and chemical properties is seen on several naturallyoccurring surfaces and is an important element in the generation of high levels of water repellence [15].

Wenzel was the first to account for the effect of roughness on an observed contact angle [16]. Others have since built upon his work to develop models which more accurately account for the influence of surface topography on water contact angles [10], [17]. These studies have demonstrated that the effect of increased roughness is usually to decrease the inherent wettability of the surface.

Methods of generating superhydrophobic surfaces have typically followed two routes: 1) the roughening of innately hydrophobic surfaces, and; 2) the use of a low surface free energy (SFE) materials to coat and hence modify pre-existing surface roughness [12]. The latter case allows for the switching of a naturally hydrophilic surface to a hydrophobic one.

Low SFE coating materials increase a surface's anti-wetting characteristics by lowering the influence of the surface chemistry at its liquid/solid/vapour interface by creating a compound air-surface, making it more energetically favourable for the water to bead rather than spread. Table 1 lists the SFE values demonstrated by some commonly-used hydrophobic materials.

\begin{tabular}{|l|l|l|l|l|}
\hline Functional group & $\mathrm{CH}_{2}$ & $-\mathrm{CH}_{3}$ & $\mathrm{CF}_{2}$ & $-\mathrm{CF}_{3}$ \\
\hline $\mathrm{SFE}\left(\mathrm{mN} / \mathrm{m}^{-1}\right)$ & 36 & 30 & 23 & 15 \\
\hline
\end{tabular}

Table 1: Decrease in surface free energy of materials [18]. 
Examples of coatings where these are found include: Polydimethylsiloxane (PDMS), Polytetrafluoroethylene (PTFE) and Fluoroalkyl silane (FAS), which have $-\mathrm{CH}_{3},-\mathrm{CF}_{2}$ and $-\mathrm{CF}_{3}$ functionalities respectively. FAS is a generic name applied to a group of molecules with similar structures and which usually have: a Si-O backbone; hydroxyl/alkoxy functionality, and; $\mathrm{CF}_{2} /-\mathrm{CF}_{3}$ pendant groups. The former allows for crosslinking and surface bonding, whilst the latter enables these polymers to confer exceptionally low SFE when applied as coatings. When all of these materials are combined with tailored, multi-level surface roughness they have been shown to exhibit ultrahydrophobic and/or superhydrophobic properties. PDMS, for example, has found widespread use in non-wetting surfaces [19], [20] and PTFE can be considered a datum low surface free energy material against which others can be compared [18]. PTFE is commonly-used used for release surface applications [21], [22]; the potential efficacy of fluorine-containing low SFE surfaces is clear from Table 1.

For this reason fluoropolymers find widespread use and several reports detail how PU surfaces can be made ultrahydrophobic or superhydrophobic by the incorporation of fluorine-containing species by direct fluorination. Examples include the modification of molecular chains during PU polymer synthesis [23]-[25] and the use of plasma treatment to impart fluorine species into the 'as received' PU [26].

Application of fluorosilane-based coatings is another method of application and allows for the deposition of $-\mathrm{CF}_{2}$ and $-\mathrm{CF}_{3}$ moieties onto the surface in a concentrated and controlled manner.

Table 1 shows that the $-\mathrm{CF}_{3}$ group is superior to the $-\mathrm{CF}_{2}$, as seen in a PTFE polymer. FAS molecules terminating with such $-\mathrm{CF}_{3}$ groups have been used to achieve superhydrophobic surfaces [27]-[30] with WCA's as high as $166^{\circ}$ [31] observed, and for this reason FAS coating chemistry is used in the present study.

A number of methods are available for achieving the multi-level roughness which, as mentioned, is critical to achieving superhydrophobicity. Examples of roughening mechanisms include: abrasive media; acid etching, and anodising [27], [32]. However, in the present study, the use of a filled PU polymer paint coating as a substrate material precludes many of these conventional methods. However, the 
presence of a substantial amount of barium sulphate in the PU coating formulation presents a method of generating roughness by preferential removal of the PU matrix material. To achieve this, an oxygen/argon plasma treatment was used in the present study.

Plasma processing is well-known to interact with polymers through two mechanisms: 1). modification of surface chemistry via chain scission leading to oxidation or controlled chemical modification, and; 2). differential ablation of dissimilar materials. Chemical modification occurs when the excited gas species generated in the plasma, including oxygen radicals and ions in the form of $\mathrm{O}^{+}, \mathrm{O}^{-}, \mathrm{O}_{2}^{-}$react with the surface. The resultant reactions impart polar functional groups including carbonate and carbonyl [33] which are favourable to surface wetting and promoting the possible formation of covalent bonds between the surface and a subsequently-applied adhesive or coating [34].

In the present study, an oxygen/argon plasma was used. In this case, in addition to the changes in surface chemistry associated with the oxygen, argon will interact with the PU surface via a purely physical sputtering removal mechanism with the mechanical impacting of the argon atoms leading to the subsequent ejection of surface species [35]. Differential ablation occurs when the materials undergoing such impact events, and which have different sputter yields, react differently to the presence of the plasma, preferentially removing specific phases present. Studies that have exploited the differing ablation rate of a material have used both the amorphous and crystalline regions of polypropylene [36] and the phenolic and linear parts of PET polymers [37] to achieve this effect. After plasma treatment the surface condition can, however, be unstable and susceptible to change [38]. For example, after the creation of a non-wetting surface by means of a plasma treatment, a number of reports have detailed at least partial recovery of wettability and have provided an explanation of the mechanisms behind the observed reversion [39], [40]. It is suggested that the plasma-induced functional groups diffuse to, or from, the surface to optimise surface energy or surface layer reorientation. In principle, in the present study, however, the combined effect of both oxidation and sputtering mechanisms should increase the SFE and wettability [34], [41] of the PU paint 
creating an optimised surface for subsequent FAS coating. The FAS-coated surface should not, in, principle undergo reversion.

Several studies have sought to take advantage of the changes in surface stoichiometry and/or roughness that a plasma process can impart to a treated surface [42]-[46]. In this study, however, we rely on the plasma for surface conditioning only prior to the application of the low energy fluorosilane coating.

In the present study, a commercial PU paint was modified to optimise hydrophobicity. To achieve this, the PU paint was FAS coated both with and without oxygen/argon plasma pretreatment. In this study, the changes to the surface appearance during the plasma treatment as well as topography and chemistry have been determined. An optimisation has also been carried out to determine the most effective FAS deposition conditions. The changes introduced, at all stages, to the surface texture were monitored by both field emission gun scanning electron microscopy (FEGSEM) and atomic force microscopy (AFM) whilst modifications to the outermost surface chemistry were studied by X-ray photoelectron spectroscopy (XPS) The resultant influence on surface wettability was monitored in the as-modified and aged conditions using contact angle analysis (CAA) using the recently-advanced drop method.

\section{Experimental}

\subsection{Materials and Processes}

The paint was IP6 2-pack PU Low VOC, formulated by Indestructible Paints Co. Ltd, Birmingham, and which comprised the following components:

Resins: $\quad$ Branched hydroxyl-bearing polyester and an aliphatic polyisocyanate;

Additives: $\quad$ Clay thickeners;

Pigments: Brifasol Red E27069, within which barium sulphate is found, and; Matting agents: including a Talc stir-in grade. 
The PU paint was spray applied to degreased-only, low carbon steel Q panels. After curing, to the manufacturer's recommended procedure, the coating thickness was 40-60 micrometres. For subsequent analysis, samples were cut from the painted $\mathrm{Q}$ panels, each measuring $20 \times 60 \times 0.6 \mathrm{~mm}$.

The fluoroalkyl silane (FAS) used was F8815, provided by Dynasylan [47]. The solution conditions for deposition of F8815 were optimised in the present study. However, for all FAS solutions, mixing took place on a standard hot plate at $200 \mathrm{rpm}$ at room temperature, for 10 minutes. The solution was applied to the PU surfaces using TechniCloth $\circledast$ non-woven wipes. Panels were left to dry for 2-24 hours before subsequent testing.

Plasma treatment was conducted using a Fishione 1020 bench-top plasma cleaning system, with a gas mixture of $25 \%$ oxygen and $75 \%$ argon at a nominal delivery pressure of $200 \mathrm{kPa}$. The machine itself is secondary plasma system, operates at a frequency of $13.56 \mathrm{MHz}$ and has ion energies of $>12 \mathrm{eV}$. Treatment periods used were up to 1200 seconds.

\subsection{Characterisation Techniques}

Field Emission Gun Scanning Electron Microscopy (FEGSEM) was carried out using a Leo 1530 VP instrument to analyse the resultant micro-scale roughness created on the PU surface from the plasma treatment. For this analysis, a primary beam energy of $5 \mathrm{KeV}$ and current of 230pA were used with an aperture size of $30 \mu \mathrm{m}$ and a working distance of $10.0 \mathrm{~mm}$.

Energy-dispersive X-ray Spectroscopy (EDS) analysis was conducted using an Oxford Instruments X-Max 80mm SDD detector to investigate the plasma treated PU surfaces. The process used an accelerating voltage of $20 \mathrm{kV}$, a probe current of approximately $1 \mathrm{nA}$ and a working distance of $8.5 \mathrm{~mm}$. In addition, an aperture of 60 $\mu \mathrm{m}$ was used to provide $>200,000$ counts per second.

Atomic force microscopy was performed using a Veeco Explorer microscope fitted with a high resonance frequency (HRF) silicon probe and operated in tapping mode. 
Surface roughness images and metrology data $\left(R_{a}\right.$ and $\left.R_{R M S}\right)$ were acquired with raster widths from $1 \times 1$ micrometre to $50 \times 50$ micrometres.

X-ray Photoelectron Spectroscopy (XPS) was conducted using a Thermo Fisher Scientific K-Alpha operating using aluminium X-rays from a monochromatic source. Survey and high resolution scans were used to quantify surface stoichiometry. Quantification was achieved using theoretically derived relative sensitivity factors based upon known ionisation cross sectional areas and the known transmission and detector functions of the analyser used. Shirley-type backgrounds were used in the calculations of the peak areas. Details of the parameters used for XPS analysis are given in Table 2.

\begin{tabular}{|l|l|l|}
\hline Parameter & Survey Scan & $\begin{array}{l}\text { High Resolution } \\
\text { Scan }\end{array}$ \\
\hline Dwell Time & $10 \mathrm{~ms}$ & $50 \mathrm{~ms}$ \\
\hline Scans & 10 & 5 \\
\hline $\begin{array}{l}\text { Total Collection } \\
\text { Time (per energy } \\
\text { step) }\end{array}$ & $100 \mathrm{~ms}$ & $250 \mathrm{~ms}$ \\
\hline $\begin{array}{l}\text { Pass Energy } \\
\text { Energy Step Size }\end{array}$ & $1.00 \mathrm{eV}$ & $50 \mathrm{eV}$ \\
\hline Analysis Area & $400 \mu \mathrm{m}$ & $0.1 \mathrm{eV}$ \\
\hline
\end{tabular}

Table 2: Parameters used for XPS analysis.

Water contact angle (WCA) analysis was carried out in order to quantify the surface wettability values of the PU coating. A Dataphysics Contact Angle System OCA was used in conjunction with the sessile drop (needle in) technique. Sigma-Aldrich HPLC analytical grade water and Sigma-Aldrich diiodomethane were the polar and nonpolar liquids respectively. Measurement involved $\geq 12$ drops, over $\geq 3$ distinct different panel areas, using $0.5 \mu \mathrm{l}$ increases in droplet size. Surface free energy values were calculated using the Owens [48] method, with the values for surface tension of the test liquids taken from Strom et al [49]. 
Colour measurements were conducted using an X-rite spectrophotometer SP60, with the CIE $1976\left(L^{*} a * b^{*}\right)$ measurement mode selected. Measurements were taken from six locations per panel: two equidistant measurements from the bottom, middle and top.

Gloss testing was conducted to ascertain the effect of plasma on surface gloss. The testing used a MG628-F2 Multi-Angle Glossmeter at $60^{\circ}$ and $20^{\circ}$ geometries.

\section{Results and Discussion}

\subsection{Plasma treatment optimisation}

The PU coatings were plasma treated for various times to determine the effect of the plasma on the surface texture. The results of FEGSEM analysis after 0 (untreated), 60, 300 and 600 seconds are presented in Figure 1.
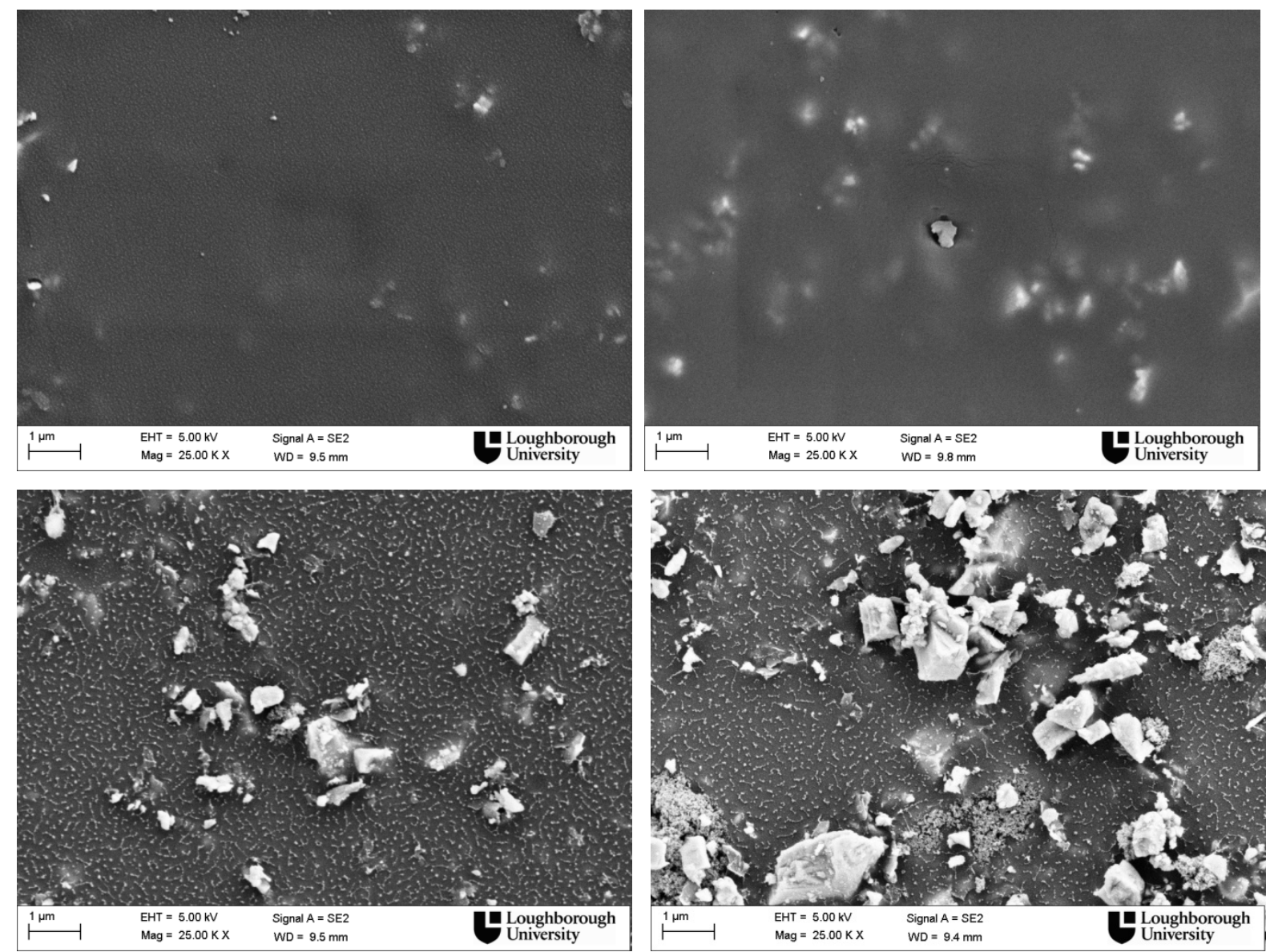
Figure 1: FEGSEM images of PU surfaces: Top left, untreated; Top right, after 60 seconds plasma exposure; Bottom left, after 300 seconds exposure, and; bottom right, after 600 seconds plasma exposure.

From Figure 1, it is apparent that the filler materials within the commercial PU coating are present in the surface region, being visible in all FEGSEM images. However, in the untreated condition (0s) the fillers are relatively unexposed and are mainly present as embedded particles within the matrix. In the untreated condition, the surface appears relatively smooth with little observed texture. After 60 s of the plasma treatment the surface appears very similar to the untreated condition. In contrast, after 300s and 600s the filler particles become much more visible as a function of increased plasma treatment time. At greater than 300s plasma exposure a multilevel roughened surface is apparent with topographic features on both the micrometre and nanometre scale. The exposed solid filler content is predominantly the barium sulphate component of the PU, this was confirmed using EDS analysis; see Table 3.

\begin{tabular}{|l|l|l|l|l|l|l|}
\hline & $\mathbf{C}$ & $\mathbf{O}$ & $\mathbf{B a}$ & $\mathbf{S}$ & Si & Fe \\
\hline Untreated & 76.0 & 17.6 & 2.9 & 2.9 & 0.3 & 0.4 \\
\hline $\begin{array}{l}\text { 600s Plasma } \\
\text { treatment }\end{array}$ & 55.2 & 35.1 & 4.3 & 4.2 & 0.6 & 0.5 \\
\hline
\end{tabular}

Table 3: EDS compositions (atom\%, excluding $\mathrm{H}$ and $\mathrm{He}$ ) from untreated and 600s plasma treated PU coatings.

The data shows both barium and sulphur exhibiting a near exact 1:1 atomic ratio both before and after plasma treatment, consistent with barium sulphate The assertion that this is the barium sulphate from the pigment component of the paint is supported by good agreement on the EDS elemental maps shown in Figure 2. 

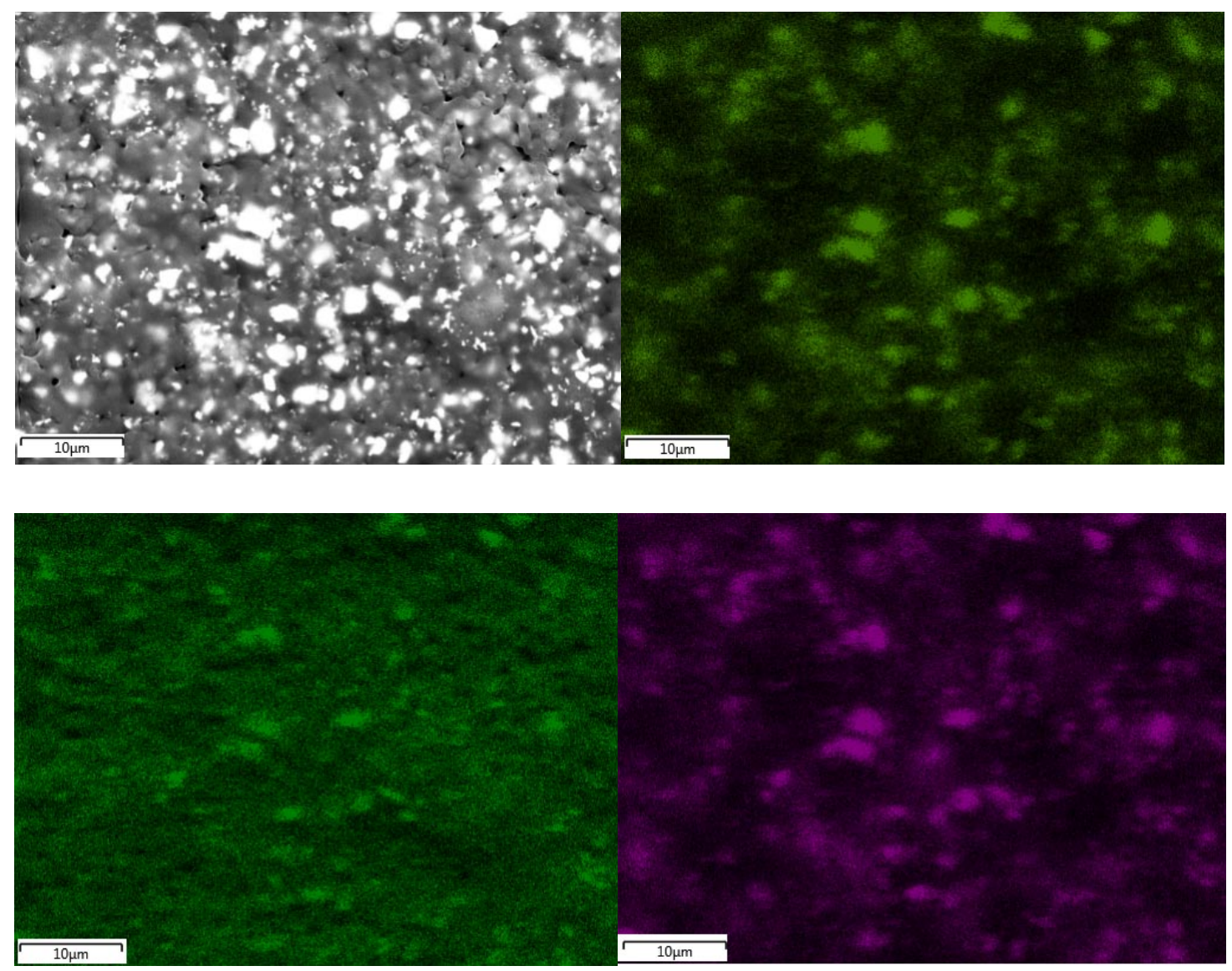

Figure 2: EDS elemental maps of 600s plasma treated PU surfaces: Top left, SEM image; Top right, barium map; Bottom left, oxygen map, and; Bottom right, sulphur map.

Importantly, the barium component incorporated into the paint formulation is insoluble in both water based solutions and organic solvents so such topographical features will be maintained after exposure to wet environments. These features can, clearly, provide the micrometre-scale surface roughening required to generate a superhydrophobic PU surface. In addition, there is nanoscale roughness generated seen as "worm-like" features surrounding the barium sulphate; see Figure 3. Initial XPS and EDS analyses were inconclusive due to the reduced sampling depth of XPS and the limited lateral resolution of EDS. However, it is likely that this is associated with the nanosilica phase present within the PU coating. 


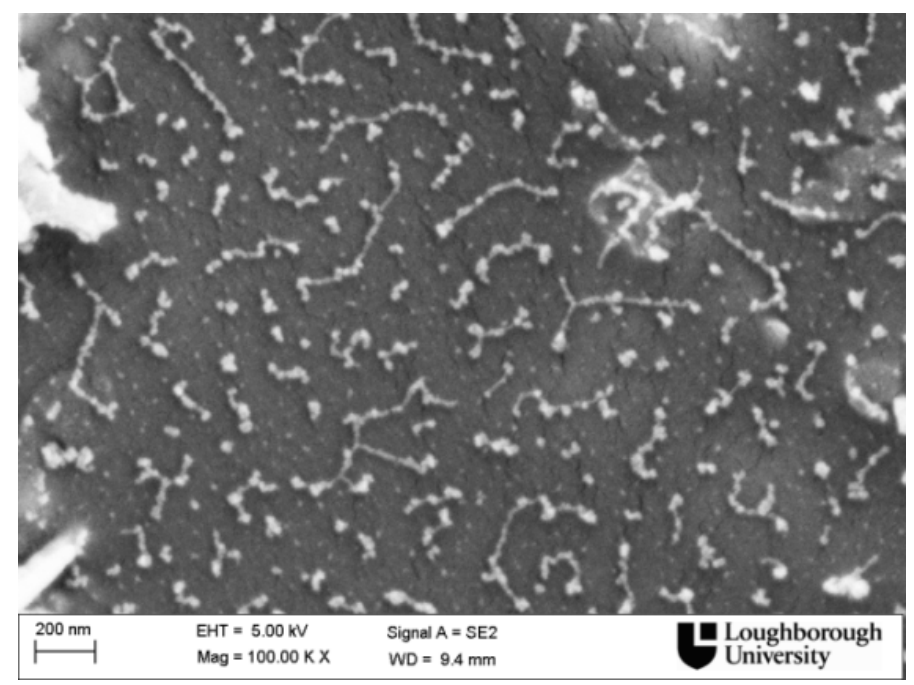

Figure 3: High resolution image of the "background" area of the PU coating after 600 s plasma treatment time.

This solid content exposure and increase in roughness is consistent with other reports on the effect of plasma on the surface of similar polyurethane films [26], [50]. AFM scans of $50 \mu \mathrm{m} \times 50 \mu \mathrm{m}$ areas were conducted to quantify this roughening effect; see Figures 4 and 5. 

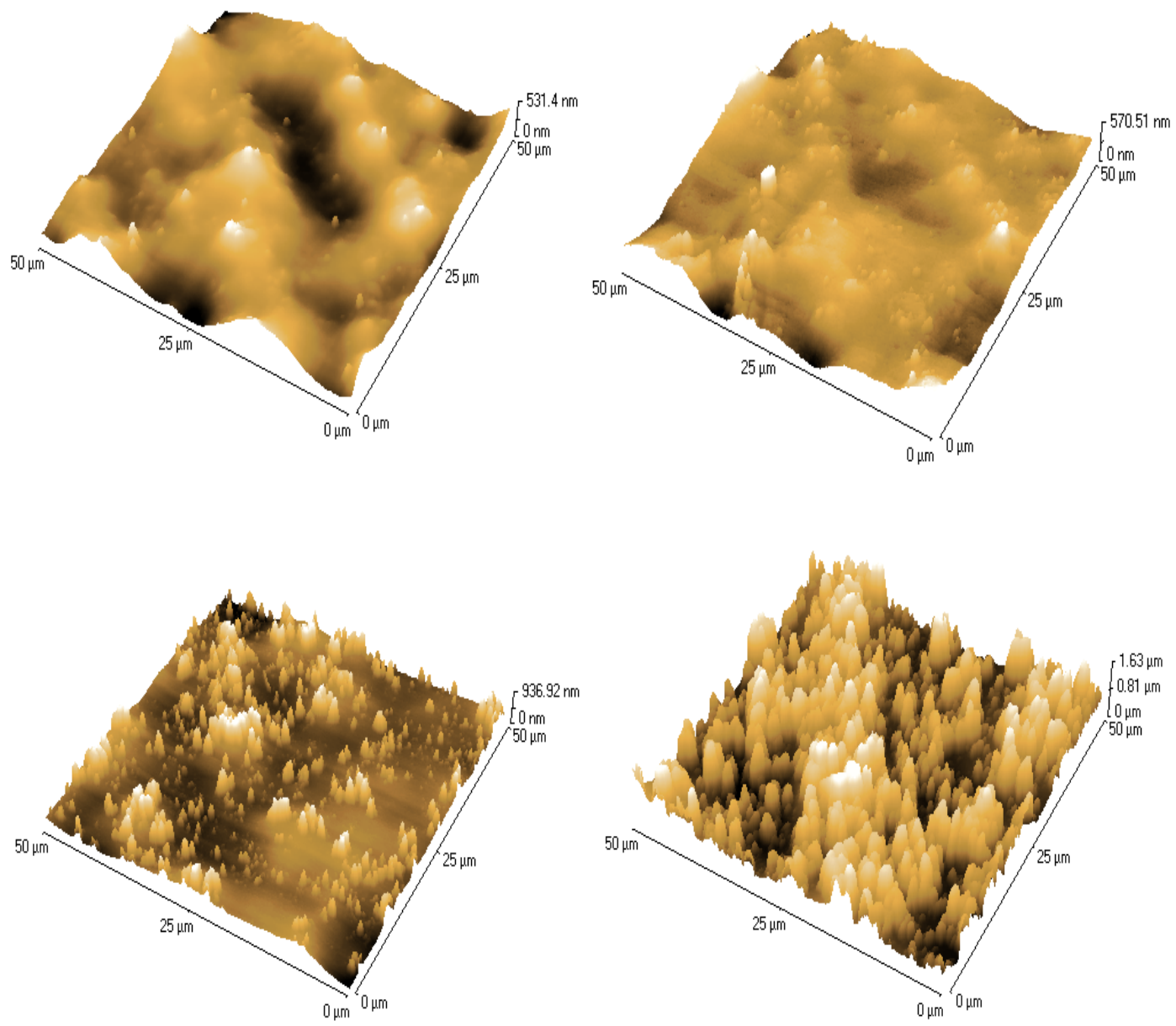

Figure 4: AFM topographical images: Top left, untreated; Top right, after 60 seconds plasma exposure; Bottom left, after 300 seconds exposure, and; Bottom right, after 600 seconds plasma exposure. 


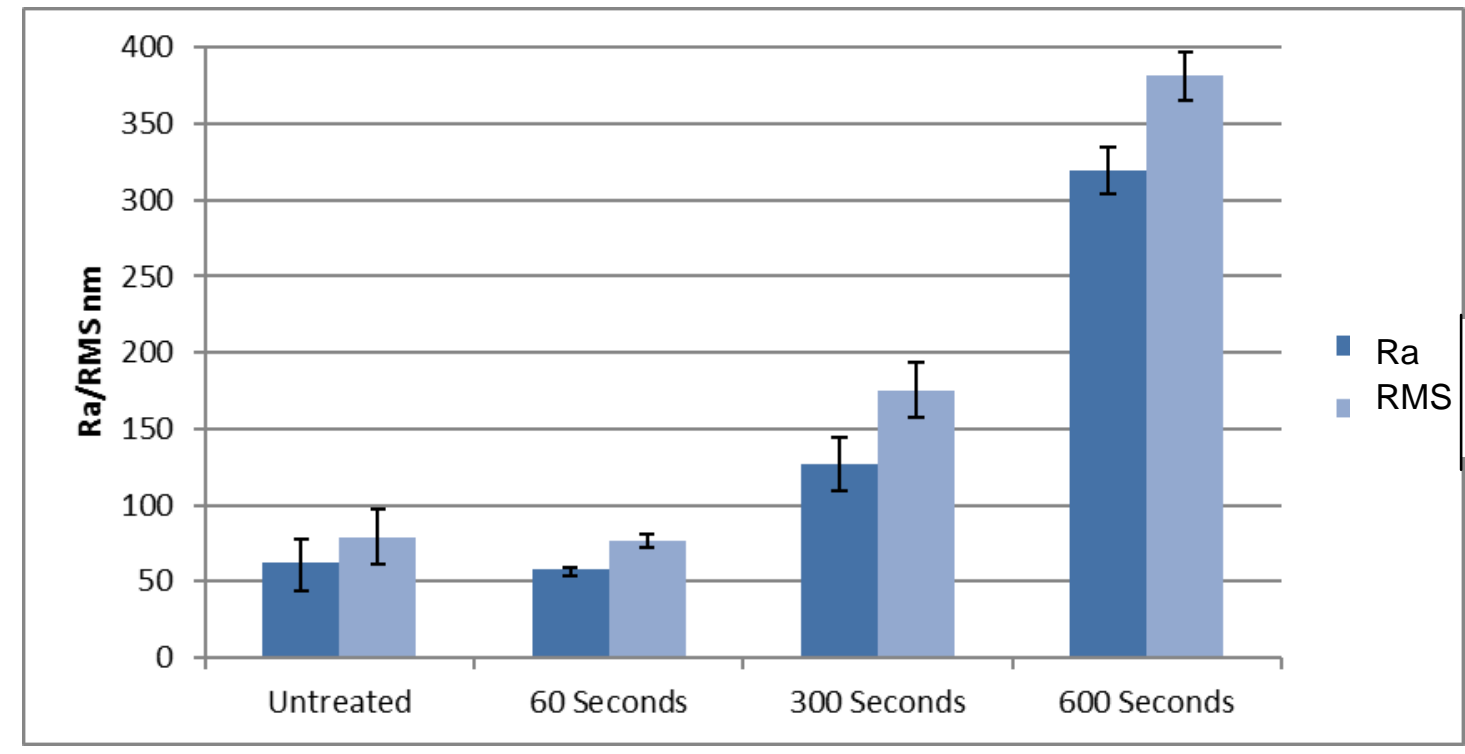

Figure 5: Averaged $R_{a}$ and $R M S$ values as a function of treatment time from plasma exposed PU surfaces.

The results presented in Figures 4 and 5 confirm the FEGSEM observations in that up to 60 seconds of plasma treatment has no significant effect on surface roughness with $R_{a}$ values observed of around $60 \mathrm{~nm}$ in the both untreated and 60s treated conditions. After this time there are substantial differences observed with a clear correlation between the length of plasma treatment time and a corresponding increase in surface roughness, with a $R_{a}$ value of $320 \mathrm{~nm}$ at $600 \mathrm{~s}$.

Significant changes in surface chemistry were also observed, by XPS, as a function of plasma treatment time; see Table 4.

\begin{tabular}{|l|c|c|c|c|c|c|c|c|}
\hline & $\mathbf{C}$ & $\mathbf{O}$ & $\mathbf{B a}$ & $\mathbf{S}$ & $\mathbf{S i}$ & $\mathbf{N}$ & $\mathbf{C l}$ & $\mathbf{P}$ \\
\hline $\begin{array}{l}\mathbf{6 0} \text { Seconds } \\
\text { Plasma }\end{array}$ & 65.62 & 23.93 & - & - & 2.07 & 8.06 & - & - \\
\hline $\begin{array}{l}\mathbf{3 0 0} \text { Seconds } \\
\text { Plasma }\end{array}$ & 60.57 & 27.16 & 0.62 & 0.75 & 3.02 & 7.36 & 0.52 & 0.32 \\
\hline $\begin{array}{l}\mathbf{6 0 0} \text { Seconds } \\
\text { Plasma }\end{array}$ & 53.16 & 31.1 & 1.5 & 1.38 & 4.97 & 6.53 & 0.23 & 1.12 \\
\hline
\end{tabular}

Table 4: XPS compositions (atom\%, excluding $\mathrm{H}$ and $\mathrm{He}$ ) from untreated and plasma treated PU coatings.

Although not long enough to increase surface roughness, the XPS data shows that 60 seconds is sufficient time to impart noteworthy chemical changes. Specifically, compared to the untreated PU, after 60s plasma treatment there is an increase in 
surface oxygen and nitrogen and the appearance of low levels of phosphorus and barium this is accompanied by a reduction in the carbon level. After 300 and 600 seconds treatment there are substantial changes in surface chemistry consistent with plasma treatment. When compared with the untreated surface, the carbon content for 600 seconds shows a reduction of $26.7 \%$ from 72.44 at.\% to 53.08 , and an increase in surface oxygen species, up 66.9\% from 19.69 at.\% to 32.88 at.\%. Overall, for treatment times up to 600s, there is a reduction in the ratio of $\mathrm{C}: \mathrm{O}$ with increasing surface exposure time to the plasma. Although some of the oxygen observed is associated with the inorganic fillers, there is also evidence of carbonyl and carboxylic acid groups on the PU surface created by the oxygen/argon plasma; see Table 5.

\begin{tabular}{|l|c|c|c|c|}
\hline Peak/Element & \multicolumn{2}{|c|}{ Untreated Control } & 600s Plasma Treatment \\
\hline & Peak BE eV & Atomic \% & Peak BE eV & Atomic \% \\
\hline C1s C-C/C-H & 285.21 & 46.12 & 285.25 & 29.66 \\
\hline C1s O=C-O & 289.41 & 5.78 & 289.44 & 7.46 \\
\hline C1s C-O (OH) & 286.68 & 20.49 & 286.57 & 13.6 \\
\hline C1s C=O & 288.27 & 0.05 & 288.06 & 2.45 \\
\hline Si2p & 102.57 & 3.54 & 103.77 & 4.97 \\
\hline N1s & 400.20 & 4.32 & 400.29 & 6.53 \\
\hline O1s O=C & 532.54 & 11.29 & 532.03 & 15.98 \\
\hline O1s O-C & 533.61 & 8.4 & 533.24 & 15.27 \\
\hline P2p & 134.96 & 0.00 & 134.96 & 1.12 \\
\hline Ba3d & 780.51 & 0.00 & 780.51 & 1.5 \\
\hline S2p & 169.0 & 0.00 & 169.0 & 1.45 \\
\hline
\end{tabular}

Table 5: XPS compositions (atom\%, excluding $\mathrm{H}$ and $\mathrm{He}$ ) and high resolution peak binding energies (BE) from untreated $\mathrm{PU}$ and after 600s plasma treatment.

The combined effect of the aforementioned changes in roughness and chemistry is a decrease in water contact angles (WCA) and a corresponding increase in apparent surface free energy SFE; see Figures 6 and 7 . It can be seen from Figure 7 that the 
untreated PU paint has an apparent SFE value of approximately $52 \mathrm{mN} / \mathrm{m}$, this value increases to $80 \mathrm{mN} / \mathrm{N}$ after $600 \mathrm{~s}$ of plasma treatment.

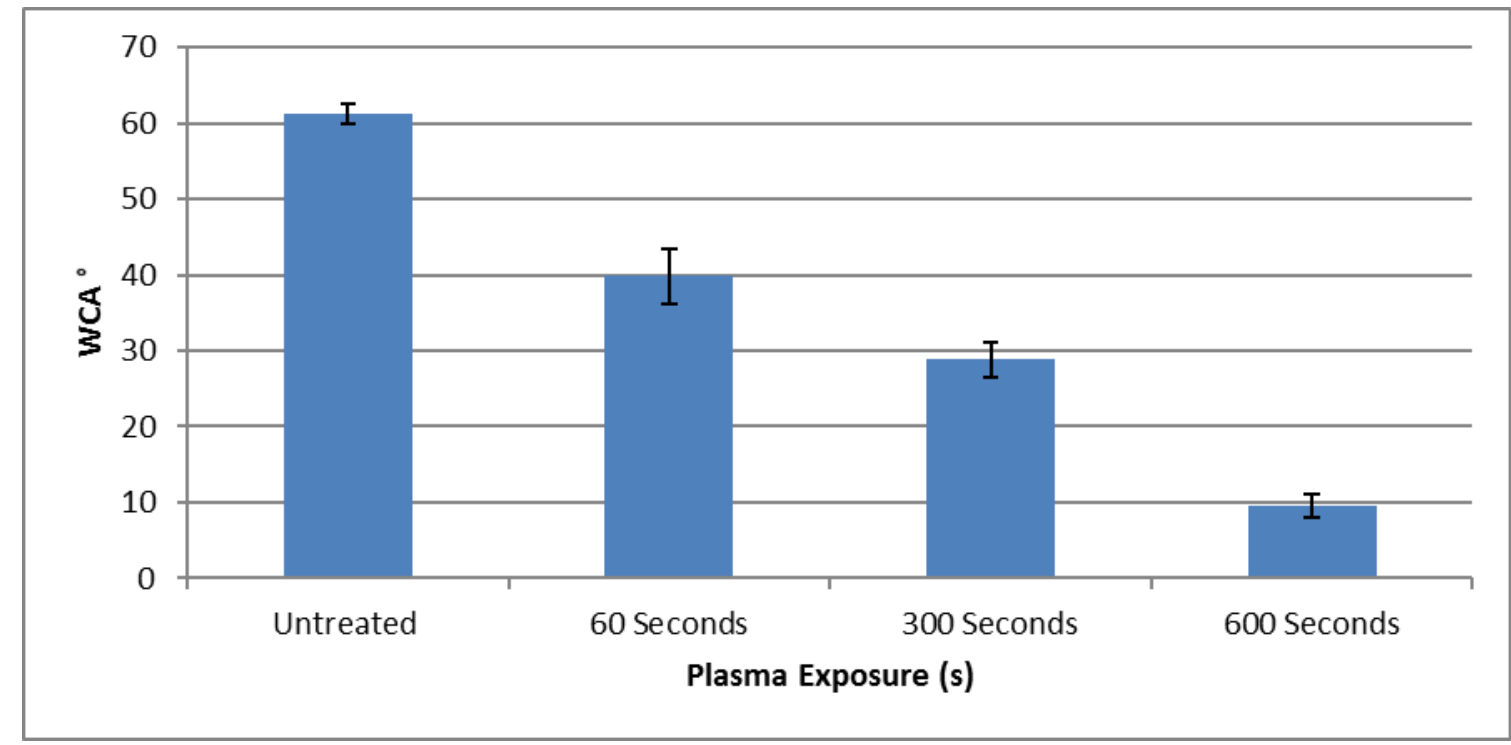

Figure 6: Measured water contact angle $\left(^{\circ}\right)$ as a function of plasma treatment time (s).

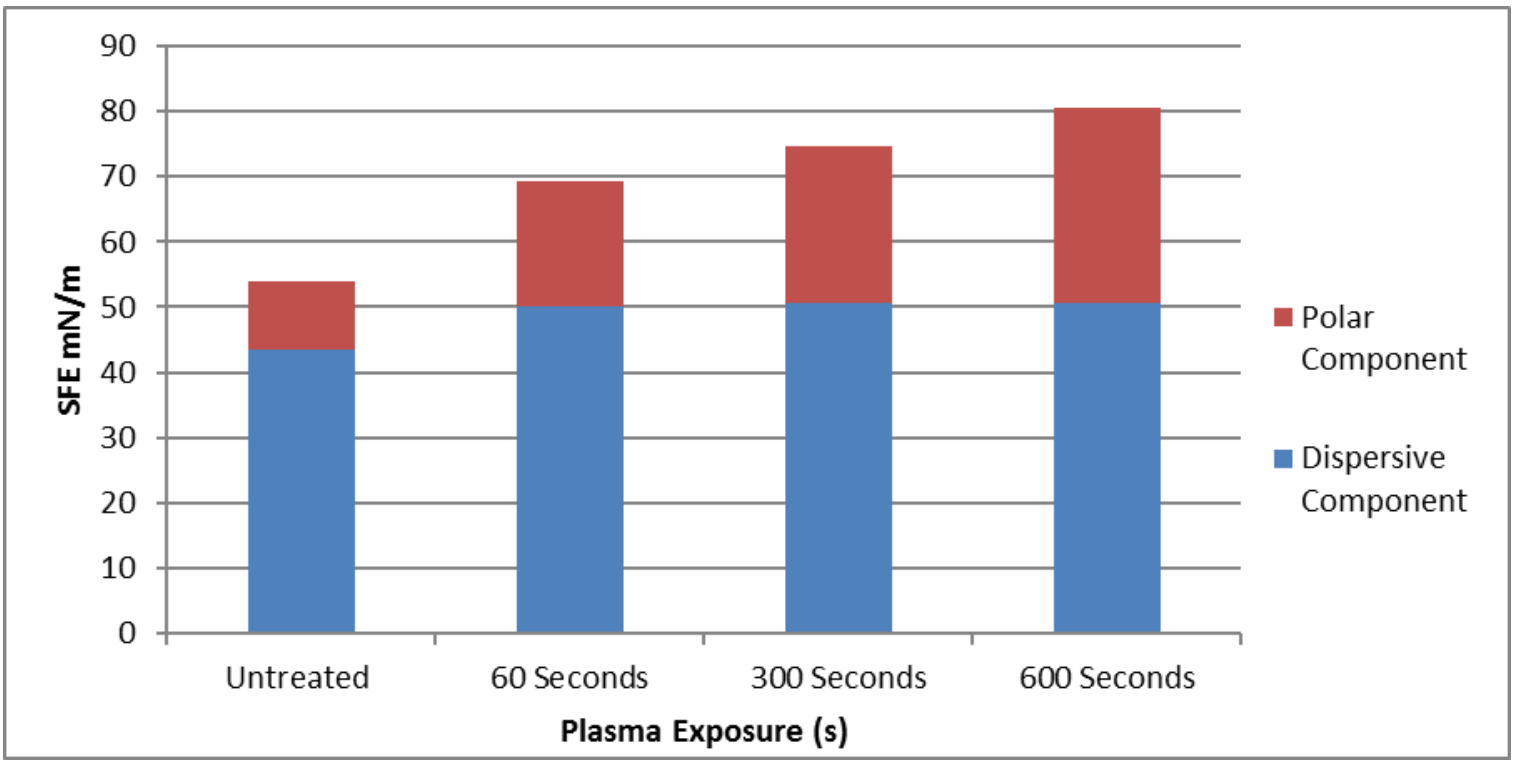

Figure 7: Measured surface free energy values $(\mathrm{mN} / \mathrm{m})$ in terms of both polar and dispersive components as a function of plasma treatment time (s).

It can also be seen from Figures 6 and 7 that a large proportion of the change in water contact angle and apparent surface free energy occurs in the initial 60 seconds of plasma exposure. This is before ablation has begun to increase surface 
roughness, as indicated in Figures 1, 4 and 5. These results indicate that the measurable reduction of WCA and increase in apparent SFE are, at least in the short term, a result of changes in the surface chemistry and the introduction of oxygencontaining polar groups. This is consistent with Figure 7, which shows that the increase in apparent SFE is largely due to the increase in the influence of the polar component of the surface energy. This is the case for all plasma treatment times used in the present study.

Considering the functional performance of $\mathrm{PU}$ paints, the influence of plasma processing on both colour and gloss levels is of industrial importance and so have been measured in the present study.

The influence of plasma processing on colour, as measured in the CIELAB $L^{*}$ and $b^{*}$ values, are indicated in Figures 8 and 9. Major changes in both $L^{*}$ and $b$ * values were observed after greater than 300 seconds of plasma exposure, note that no noticeable change was observed in the $a^{*}$ values as a function of plasma processing. This is consistent with the onset of the observation of increased surface roughness. In addition, after 300 seconds there was a small but significant increase in lightness and yellowness of the surface. Such a change in colouration is consistent with the photo-oxidation and degradation that UV light is known to have on PU. The mechanism responsible for this is thought to involve the formation of a yellow chromophoric reaction product, created when the methylene group within the $P U$ is oxidised and the urethane groups experience chain scission [51].

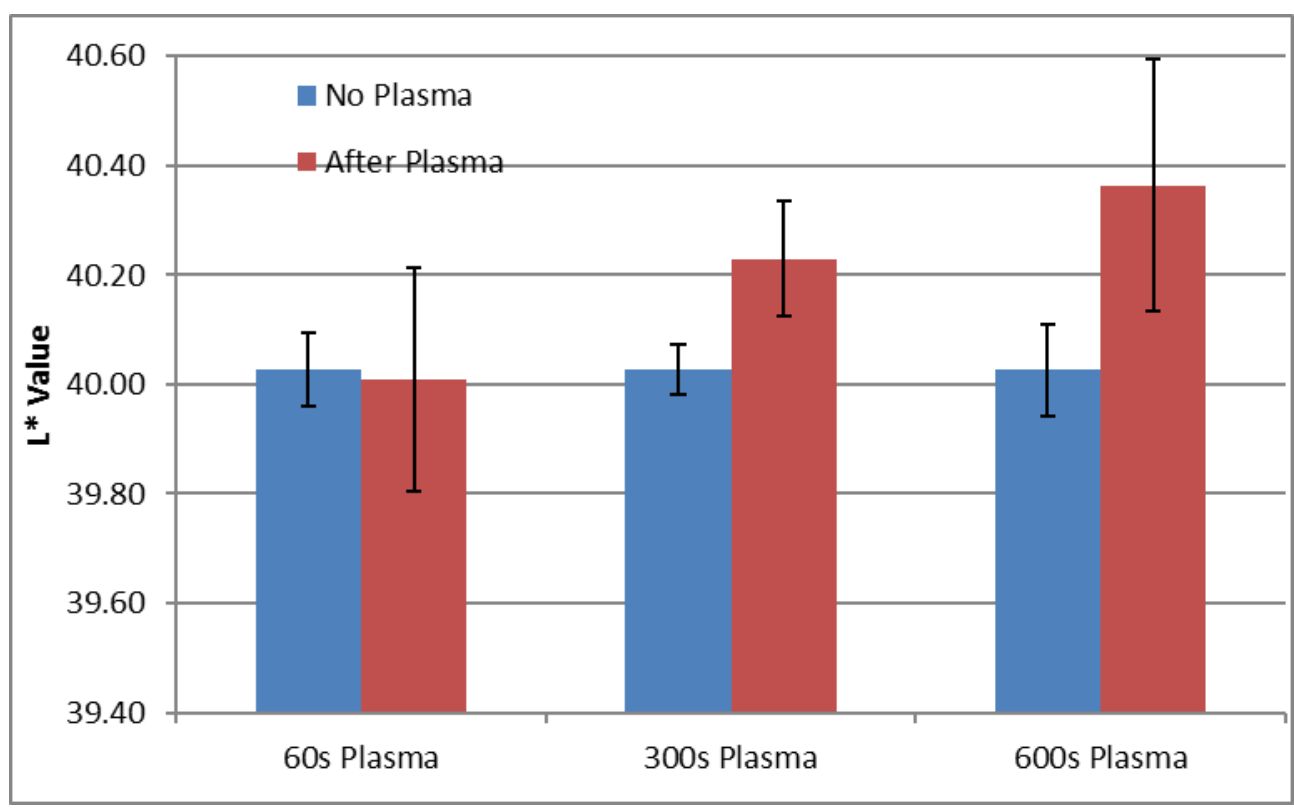


Figure 8: $L^{*}$ values for both untreated and plasma treated PU coatings as a function of treatment time (s).

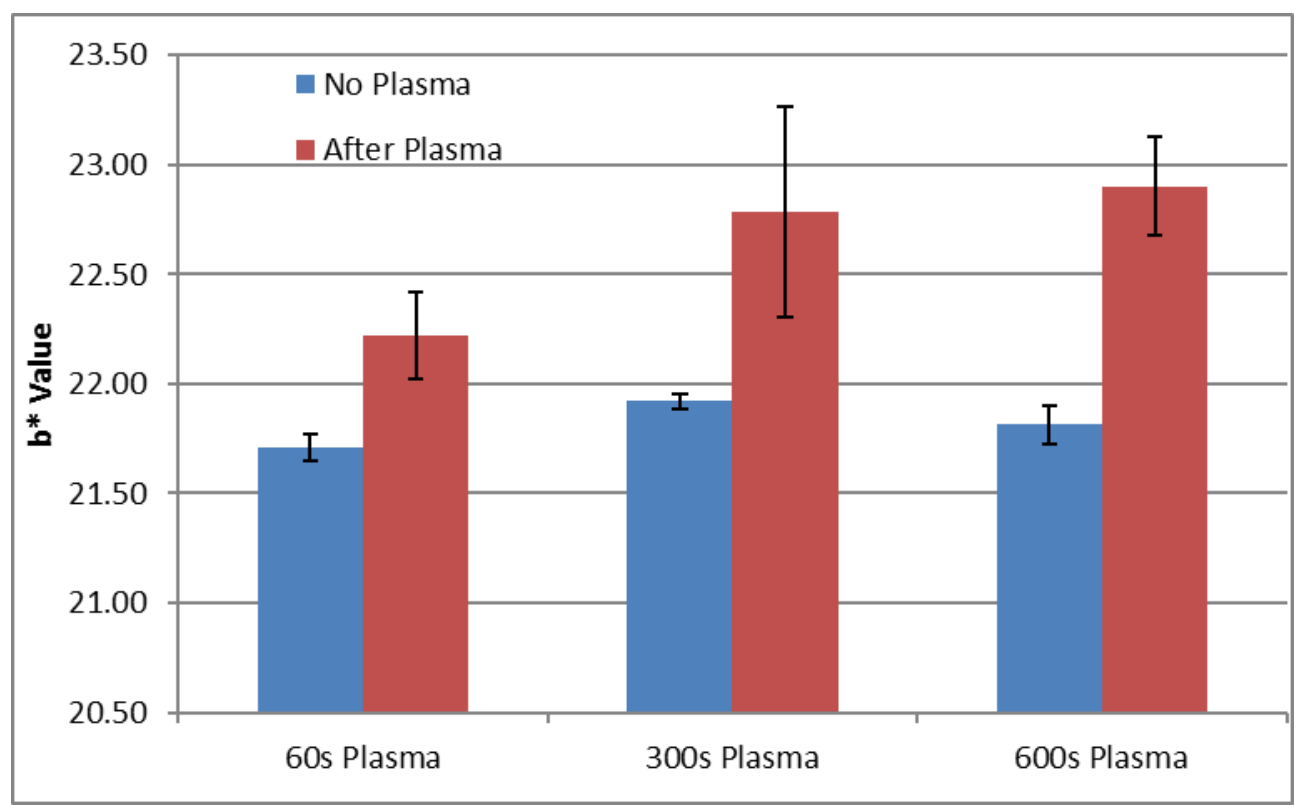

Figure 9: $b^{*}$ values for both untreated and plasma treated PU coatings as a function of treatment time (s).

In terms of gloss, this is, to some degree, a qualitative surface characteristic subject to individual perceptions but the most commonly known and quantifiable aspect of gloss is the measure of specular reflected light. This is one of two reflections which emanate from the interaction of an incident beam of light with a surface and manifests itself in the perception of a shiny surface [52], [53]. Roughness plays a critical role in the amount of this specular gloss which emanates from a surface. Its effect can be quantified using both the Raleigh Criterion and the Bennet-Porteus equation; both of which show that roughness has the effect of reducing gloss levels [53]. Reduced surface roughness is therefore desirable to maximise specular reflection and to minimise diffuse reflection [3]. The increase in roughness resulting from the plasma treatments, as indicated in Figures 1, 4 and 5, therefore would be expected to decrease gloss levels. This effect was clearly observed; see Figures 10 and 11 which show gloss levels at $20^{\circ}$ and $60^{\circ}$ incident light angles respectively. The topographic or roughness induced scattering effect occurs as a result of sputtering or 
photo-oxidation exposing the light scattering particles in the $\mathrm{PU}$, thereby, reducing gloss levels [54].

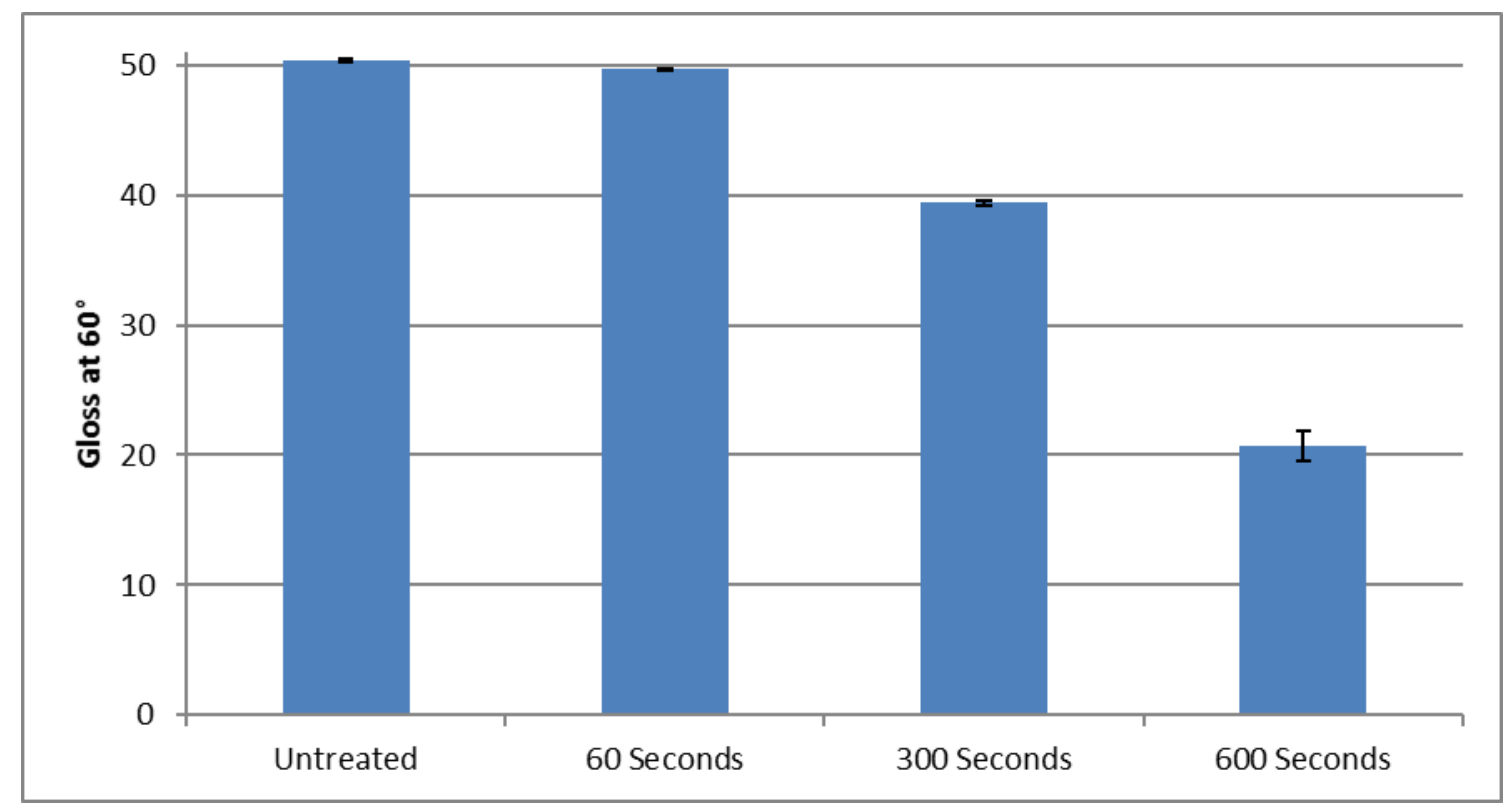

Figure 10: Gloss readings at $60^{\circ}$ incident angle as a function of plasma treatment time (s).

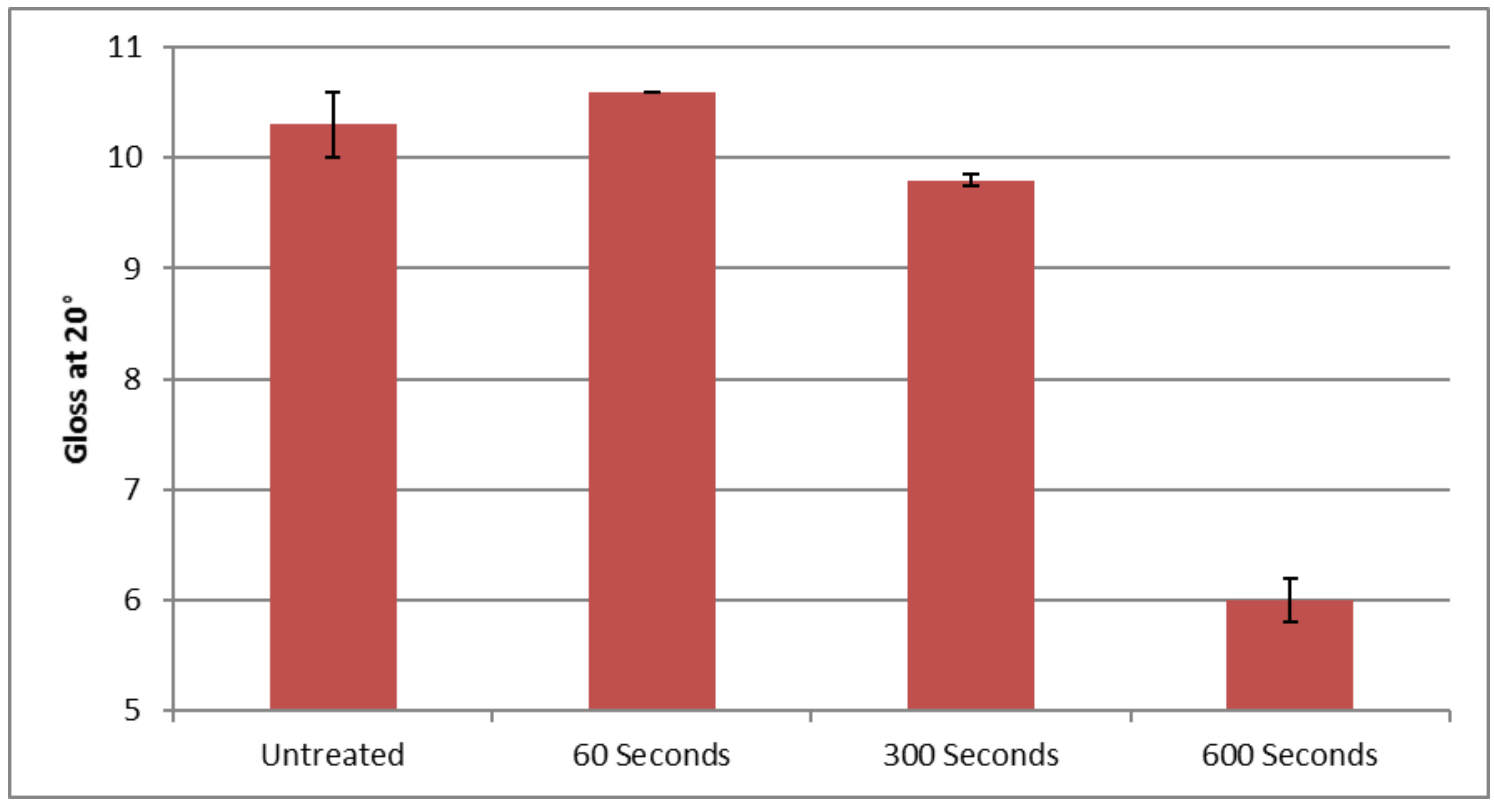

Figure 11: Gloss readings at $20^{\circ}$ incident angle as a function of plasma treatment time (s). 
In summary, the effect of oxygen/argon plasma treatment for 600 s on a commercial $\mathrm{PU}$ paint coating is to create a multi-scale, nanometre- and micrometre-rough, surface which is highly wettable and containing advantageous functional groups suitable for subsequent coating. The optical properties in terms of colour and gloss, however, are reduced due to the induced roughness and chemical modification. For the present study, these disadvantages were not of concern, the 600s oxygen/argon plasma process was then considered further as a pretreatment for the subsequent deposition of the hydrophobic FAS coating.

\subsection{Fluoroalkyl silane (FAS) optimisation}

For a specific FAS type, the deposition of optimised films is dependent upon a number of critical parameters, these include: solution concentration; solvent type; solution $\mathrm{pH}$, and; hydrolysis or drying conditions. A number of these will be discussed below for the chosen FAS, Dynasylan F8815.

The effect on both apparent SFE and WCA of F8815 polymer concentration, in methanol, when applied to the untreated PU coating can be seen in Figures 12 and 13. Note that the values recorded in Figures 12 and 13 were acquired less than 2 hours after FAS deposition and should be regarded as initial values, used for screening purposes only. It is known that increased stabilisation times can increase the observed WCA and apparent SFE values, and the values presented in Figure 14 were obtained after a more extensive 24 hour stabilisation period. 


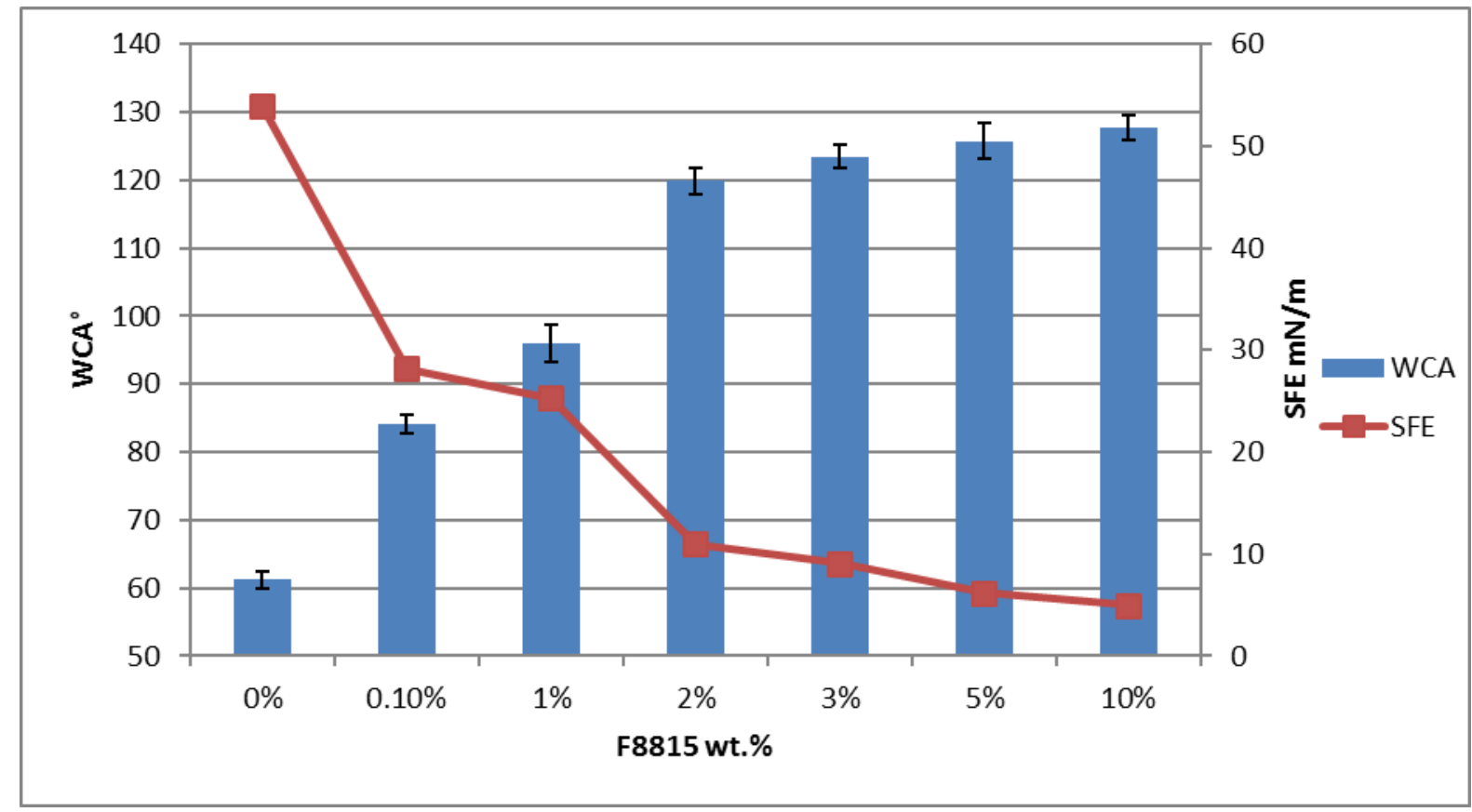

Figure 12: Water contact angle $\left({ }^{\circ}\right.$, bars) and apparent surface free energy $(\mathrm{mN} / \mathrm{m}$, line) values as a function of $\mathrm{F8815}$ concentration (\%) in methanol.

With no FAS applied, the WCA value of the as-painted PU was approximately $60^{\circ}$ with an apparent surface free energy of over $50 \mathrm{mN} / \mathrm{m}$. The WCA value clearly increases rapidly and the apparent SFE consequently decreases with even low levels of FAS in solution. The results though show a rapid increase in the hydrophobicity of the surface up to $2 w t . \%$ FAS, before a more gradual increase is observed past this point. A concentration of $3 w t . \%$ was chosen for further development since all measurements taken at this concentration, or greater, demonstrated the required ultra-hydrophobicity. It was able to achieve this purely through changes in surface chemistry; see Table 6. AFM showed no change in PU surface roughness with or without FAS application.

\begin{tabular}{|l|l|l|l|l|l|}
\hline Sample & $\mathbf{C}$ & $\mathbf{F}$ & $\mathbf{N}$ & $\mathbf{O}$ & $\mathbf{S i}$ \\
\hline Untreated & 72.6 & 0.0 & 4.3 & 10.0 & 4.1 \\
\hline 3\% FAS & 40.0 & 42.0 & 2.3 & 10.6 & 5.2 \\
\hline
\end{tabular}

Table 6: XPS compositions (atom\%, excluding $\mathrm{H}$ and $\mathrm{He}$ ) from untreated and 3\% FAS treated PU coatings. 
It is known that the efficacy of a silane deposition can be affected by a number of influencing factors, one of which is solution $\mathrm{pH}$. For this study, the 3\% FAS and methanol solution was $\mathrm{pH}$ adjusted using sodium hydroxide and acetic acid, in increments of 1 from the solution's unaltered $\mathrm{pH}$ of 6.49. The results presented in Figure 13 show that acidity has no impact on the hydrophobicity of the resultant deposit. In contrast, the basicity does have a marked effect on the functionality of the FAS film.

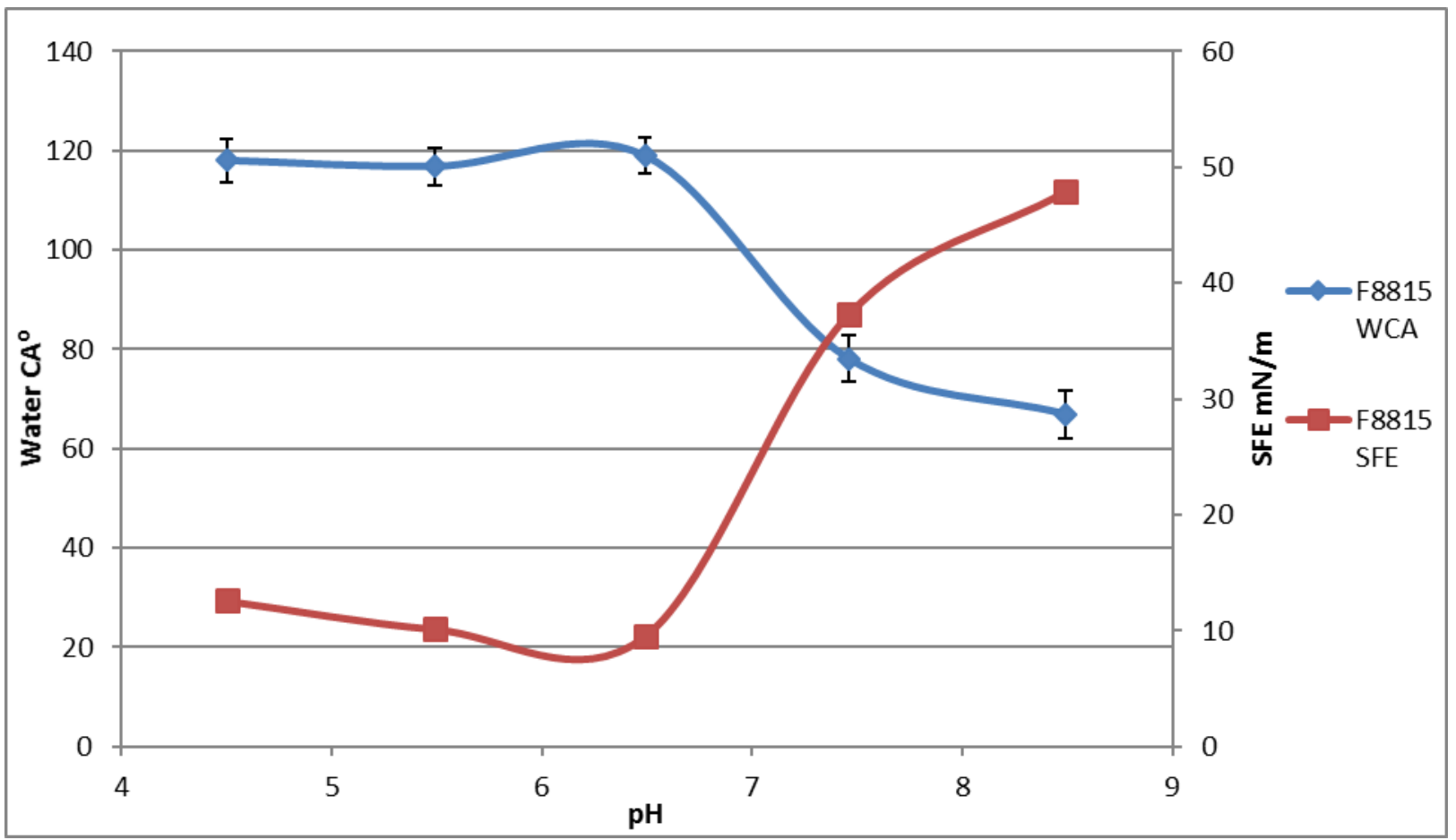

Figure 13: Water contact angle $\left({ }^{\circ}\right.$, circles) and apparent surface free energy ( $\mathrm{mN} / \mathrm{m}$, squares) values as a function of $\mathrm{F8815}$ solution $\mathrm{pH}$.

Related work has shown that at the deposition of organosilane films from low silanol concentrations (0.1 and 1\%) deposit effectively under acidic conditions compared to higher $\mathrm{pH}$ values or more basic conditions [55].

Other deposition parameters such as: drying conditions; different solvent, and; the amount of water in solution were also studied. It was found that drying conditions showed no effect on the hydrophobicity of the surface, with both air drying for 24 
hours and localised hot air drying for two minutes showing no improvement in the contact angle or SFE of the FAS treated surface. In addition, hexane proved an ineffective solvent and produced relatively low contact angle and high SFE values comparable to that of an untreated surface. In terms of water content in solution, the presence of 1,5 and $10 \%$ water content had no positive effect on surface hydrophobicity or SFE of the polymer. F8815 is an aqueous based system and the molecule itself is hydroxyl terminated [47] and does therefore not require the presence of additional water to facilitate a hydrolysis reaction in solution. From these studies, optimised FAS deposition conditions were determined on non-plasma treated PU coatings.

A control experiment was also carried out to determine the stability of the plasmatreated PU surface to solvent exposure. In this experiment, a 600s plasma treated panel was wiped with methanol and subsequently analysed by XPS. The aim of this was to establish any changes in surface chemistry introduced by solvent exposure only which might be associated with the removal of a weakly-bound or friable oxidised layer on the plasma processed PU surface. In this way it is also possible to isolate the effect of the solvent when it is not combined with the F8815 polymer. The changes in surface chemistry as a result of methanol exposure, and observed by XPS, can be seen in Table 7. From Table 7, it can be seen that there is a general reduction in the levels of $\mathrm{P}, \mathrm{Ba}$ and $\mathrm{S}$ observed and an increase in $\mathrm{C}-\mathrm{O}$ bonding as a consequence of methanol wiping. It is not, however, clear whether these changes are due to the removal of some weakly-bound or low molecular weight materials created during plasma processing or due to masking by strongly adsorbed methanol on to the previously high energy surface. It is, however, clear that there are still significant $\mathrm{C}-\mathrm{O}$ and $\mathrm{C}=\mathrm{O}$ functionalities present on the solvent wiped surface which indicate that the influence of plasma processing is still present post solvent wiping. 


\begin{tabular}{|l|c|c|c|c|}
\hline \multirow{2}{*}{ Peak/Element } & \multicolumn{2}{|c|}{ 600s Plasma Treatment } & $\begin{array}{r}\text { 600s Plasma Treatment + } \\
\text { Methanol Wipe }\end{array}$ \\
\hline & Peak BE eV & Atomic \% & Peak BE eV & Atomic \% \\
\hline C1s C-C/C-H & 285.25 & 29.66 & 284.72 & 32.91 \\
\hline C1s O=C-O & 289.44 & 7.46 & 289.02 & 5.9 \\
\hline C1s C-O (OH) & 286.57 & 13.6 & 285.86 & 23.99 \\
\hline C1s C=O & 288.06 & 2.45 & 287.9 & 2.68 \\
\hline Si2p & 103.77 & 4.97 & 103.12 & 1.99 \\
\hline N1s & 400.29 & 6.53 & 399.76 & 5.52 \\
\hline O1s O=C & 532.03 & 15.98 & 531.49 & 12.47 \\
\hline O1s O-C & 533.24 & 15.27 & 532.77 & 13.03 \\
\hline P2p & 134.96 & 1.12 & 133.59 & 0.53 \\
\hline Ba3d & 780.51 & 1.5 & 780.23 & 0.42 \\
\hline S2p & 169.0 & 1.45 & 168.85 & 0.55 \\
\hline
\end{tabular}

Table 7: XPS Compositions (atom\%, excluding $\mathrm{H}$ and $\mathrm{He}$ ) and high resolution peak binding energies (BE) from the following surfaces: 600s plasma treatment only and 600s plasma pretreated with methanol wipe.

\subsection{Generation of superhydrophobic PU-based surfaces}

By combining the oxygen/argon plasma pretreatment with a Dynasylan F8815 posttreatment it is thought that an ideal non-wetting surface can be generated. Figure 14 shows both the WCA and apparent surface free energy values from this combination.

From Figure 14, it can be seen that the WCA values increase markedly with treatment time from approximately $123^{\circ}$ to $153^{\circ}$ and that the apparent SFE values decrease with a value of approximately $0.8 \mathrm{mN} / \mathrm{m}$ measured after $1200 \mathrm{~s}$ of plasma treatment plus 3\% FAS applied. It can be seen that the trends in terms of WCA and apparent SFE values are the reverse of those seen in Figures 6 and 7 . 


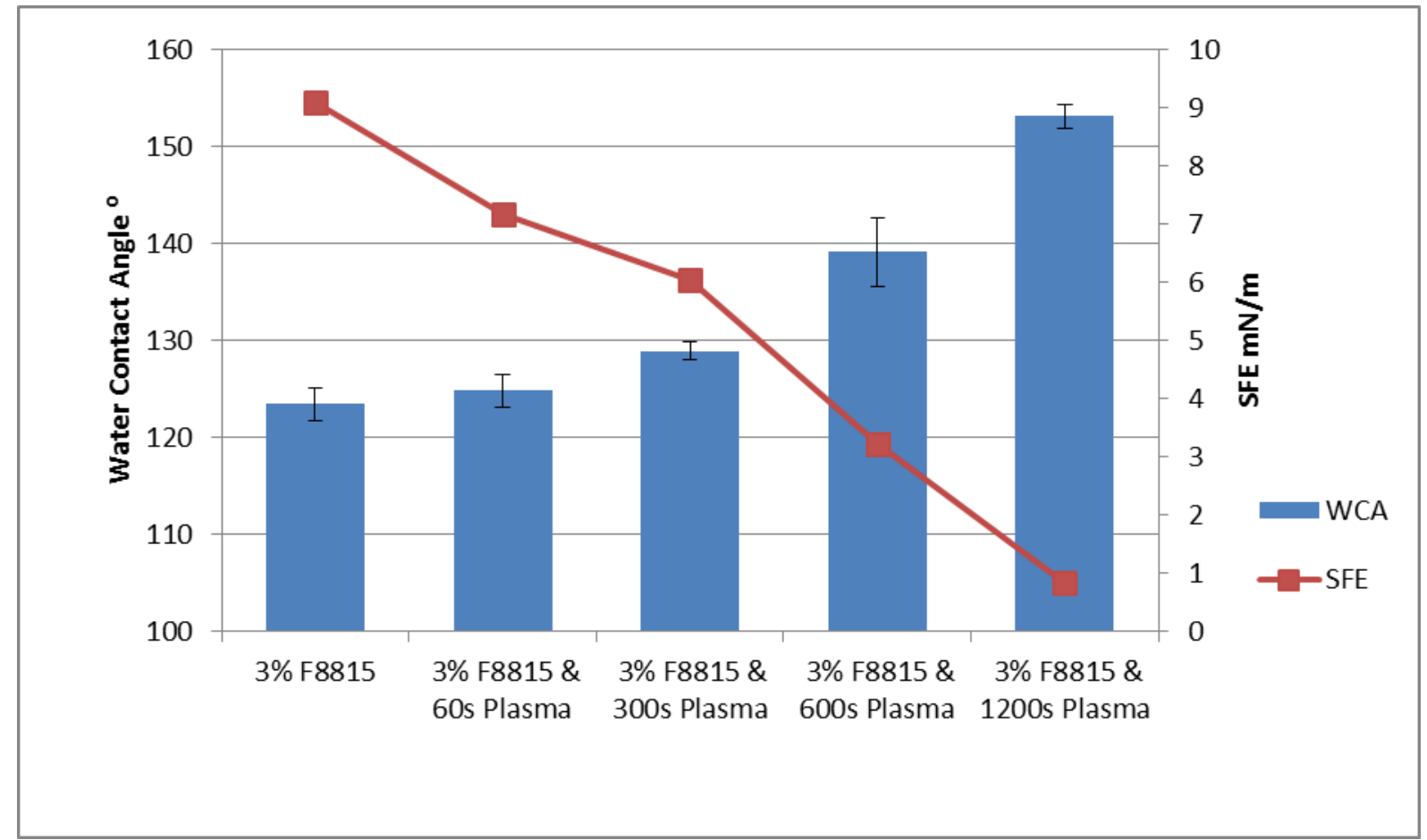

Figure 14: Water contact angle $\left({ }^{\circ}\right.$, bars) and apparent surface free energy ( $\mathrm{mN} / \mathrm{m}$, line) values after plasma processing for various times and $3 \%$ dynasylan F8815 coating.

The excellent reproducibility of these results is illustrated in Table 8 which shows WCA data for three separate painted panels after 600s of plasma pretreatment followed by immersion in 3\% F8815 FAS solution. 


\begin{tabular}{|l|l|l|l|l|l|l|l|}
\hline & $\begin{array}{l}\text { Water } \\
\text { CA }\end{array}$ & \pm & $\begin{array}{l}\text { DIM } \\
\text { CA }\end{array}$ & \pm & $\begin{array}{l}\text { Disp Comp } \\
\mathrm{mN} / \mathrm{m}\end{array}$ & $\begin{array}{l}\text { Polar } \\
\text { Comp } \\
\mathrm{mN} / \mathrm{m}\end{array}$ & $\begin{array}{l}\text { SFE } \\
\mathrm{mN} / \mathrm{m}\end{array}$ \\
\hline $\begin{array}{l}\text { 3\% F8815 } \\
\text { 600s Plasma } \\
\text { (Panel 1) }\end{array}$ & 139.1 & 3.5 & 116.8 & 0.9 & 3.84 & 0.00 & 3.84 \\
\hline $\begin{array}{l}\text { 3\% F8815 } \\
\text { 600s Plasma } \\
\text { (Panel 2) }\end{array}$ & 137.8 & 2.4 & 117.4 & 3.4 & 3.69 & 0.01 & 3.69 \\
\hline $\begin{array}{l}\text { 3\% F8815 } \\
\text { 600s Plasma } \\
\text { (Panel 3) }\end{array}$ & $\mathbf{1 3 7 . 3}$ & 2.5 & 120.1 & 2.1 & 3.21 & 0.01 & $\mathbf{3 . 2 2}$ \\
\hline
\end{tabular}

Table 8: Water and diiodomethane (DIM) contact angle data and the apparent surface free energy $(\mathrm{mN} / \mathrm{m})$ values on three separate PU painted panels after plasma processing for 600 s plus 3\% Dynasylan F8815 coating.

By increasing the PU surface wettability during the plasma phase and prior to FAS application there is excellent control over the final surface chemistry when compared to alternative processes. Furthermore, in this case, the plasma phase can be utilised to tailor surface roughness to control hydrophobicity.

XPS analysis was used to confirm the surface functionality at all stages of processing; see Tables 9 and 10. XPS provides the results of surface survey scans only and surface compositions. 


\begin{tabular}{|l|c|c|c|c|c|c|c|c|}
\hline & $\mathbf{C}$ & $\mathbf{O}$ & $\mathbf{B a}$ & $\mathbf{S}$ & $\mathbf{N}$ & $\mathbf{S i}$ & $\mathbf{P}$ & $\mathbf{F}$ \\
\hline Untreated & 72.44 & 19.69 & 0.00 & 0.00 & 4.32 & 3.54 & 0.00 & 0.00 \\
\hline $\begin{array}{l}\text { 600s } \\
\text { Plasma } \\
\text { treatment }\end{array}$ & 53.17 & 31.25 & 1.5 & 1.45 & 6.53 & 4.97 & 1.12 & 0.00 \\
\hline $\begin{array}{l}\text { Untreated } \\
\text { plus 3\% } \\
\text { F8815 }\end{array}$ & 43.88 & 8.99 & 0.00 & 0.00 & 1.19 & 5.26 & 0.00 & 40.67 \\
\hline $\begin{array}{l}\text { 600s } \\
\text { Plasma } \\
\text { plus 3\% } \\
\text { F8815 }\end{array}$ & 36.12 & 9.61 & 0.04 & 0.00 & 1.36 & 5.66 & 0.00 & 47.20 \\
\hline
\end{tabular}

Table 9: XPS data indicating surface compositions (atom\%, excluding $\mathrm{H}$ and $\mathrm{He}$ ) from the following samples: Untreated PU; 600s plasma treatment only; Untreated PU plus 3\% F8815 FAS, and 600s plasma pretreated PU plus 3\% F8815 FAS.

From the XPS data presented in Table 9, the highest level of surface fluorine is present on the modified PU paint after both plasma pretreatment plus FAS coating with over 47 at.\% present. This demonstrates the effectiveness of the plasma pretreatment. The significant reduction in the nitrogen, barium and phosphorus signals, all elements from the PU paint, show that the FAS has deposited fairly conformally. The high resolution XPS data presented in Table 10 provides additional oxidation state information. These data suggest that the $\mathrm{F}$ is present in both $-\mathrm{CF}_{2}$ and $-\mathrm{CF}_{3}$ forms. 


\begin{tabular}{|c|c|c|c|c|c|c|c|c|}
\hline \multirow[t]{2}{*}{ Peak/Element } & \multicolumn{2}{|c|}{$\begin{array}{l}\text { Untreated } \\
\text { Control }\end{array}$} & \multicolumn{2}{|c|}{$\begin{array}{c}\text { 600s Plasma } \\
\text { Treatment }\end{array}$} & \multicolumn{2}{|c|}{$\begin{array}{l}\text { Untreated plus } \\
\text { 3\% F8815 FAS }\end{array}$} & \multicolumn{2}{|c|}{$\begin{array}{c}\text { 600s Plasma } \\
\text { Pretreatment } \\
\text { plus 3\% F8815 } \\
\text { FAS }\end{array}$} \\
\hline & $\begin{array}{l}\text { Peak } \\
\text { BE eV }\end{array}$ & $\begin{array}{l}\text { Atomic } \\
\%\end{array}$ & $\begin{array}{l}\text { Peak } \\
\text { BE eV }\end{array}$ & $\begin{array}{l}\text { Atomic } \\
\%\end{array}$ & $\begin{array}{l}\text { Peak } \\
\text { BE eV }\end{array}$ & $\begin{array}{l}\text { Atomic } \\
\%\end{array}$ & $\begin{array}{l}\text { Peak } \\
\text { BE eV }\end{array}$ & $\begin{array}{l}\text { Atomic } \\
\%\end{array}$ \\
\hline $\mathrm{C} 1 \mathrm{~s} \mathrm{C}-\mathrm{C} / \mathrm{C}-\mathrm{H}$ & 285.21 & 46.12 & 285.25 & 29.66 & 285.5 & 13.10 & 285.48 & 5.61 \\
\hline $\mathrm{C} 1 \mathrm{~s} \mathrm{O}=\mathrm{C}-\mathrm{O}$ & 289.41 & 5.78 & 289.44 & 7.46 & 289.5 & 0.96 & 289.28 & 1.34 \\
\hline $\mathrm{C} 1 \mathrm{~s} \mathrm{C}-\mathrm{O}(\mathrm{OH})$ & 286.68 & 20.49 & 286.57 & 13.6 & 286.7 & 12.59 & 286.63 & 10.78 \\
\hline $\mathrm{C} 1 \mathrm{~s} \mathrm{C}=\mathrm{O}$ & 288.27 & 0.05 & 288.06 & 2.45 & 0.00 & 0.00 & 0.00 & 0.00 \\
\hline $\mathrm{C} 1 \mathrm{~s} \mathrm{C}-\mathrm{F}_{2}$ & 292.2 & 0.00 & 292.2 & 0.00 & 292.2 & 14.9 & 292.21 & 15.77 \\
\hline $\mathrm{C} 1 \mathrm{~s} \mathrm{C}-\mathrm{F}_{3}$ & 294.4 & 0.00 & 294.4 & 0.00 & 294.4 & 2.33 & 294.53 & 2.62 \\
\hline Si2p & 102.57 & 3.54 & 103.77 & 4.97 & 103.8 & 5.26 & 104 & 5.66 \\
\hline N1s & 400.20 & 4.32 & 400.29 & 6.53 & 400.0 & 1.19 & 400.42 & 1.36 \\
\hline O1s $\mathrm{O}=\mathrm{C}$ & 532.54 & 11.29 & 532.03 & 15.98 & 532.03 & 0.00 & 532.03 & 0.00 \\
\hline O1s O-C & 533.61 & 8.4 & 533.24 & 15.27 & 533.5 & 8.99 & 533.58 & 9.61 \\
\hline$P 2 p$ & 134.47 & 0.00 & 134.96 & 1.12 & 134.47 & 0.00 & 134.47 & 0.00 \\
\hline Ba3d & 780.48 & 0.00 & 780.51 & 1.5 & 780.48 & 0.00 & 781.1 & 0.04 \\
\hline$S 2 p$ & 169.0 & 0.00 & 169.0 & 1.45 & 169.0 & 0.00 & 169.0 & 0.00 \\
\hline F1s & 689.5 & 0.00 & 0.00 & 0.00 & 689.5 & 40.67 & 689.57 & 47.2 \\
\hline
\end{tabular}

Table 10: XPS compositions (atom\%, excluding $\mathrm{H}$ and $\mathrm{He}$ ) and high resolution peak binding energies (BE) from the following surfaces: Untreated PU; 600s plasma treatment only; Untreated PU Plus 3\% FAS, and 600s plasma pretreated PU plus 3\% FAS.

From a review of the available literature, such a process, for the production of a fluorosilane coating on an oxygen plasma treated polyurethane surface for improved hydrophobicity, has not been previously reported. In terms of plasma-deposition of fluorinated films, a related study by Gordon et al details the use of perfluoroalkane plasma to achieve a surface fluorine content of 9.9 at.\% and a WCA of $97.40^{\circ}$ [26]. In addition, Ward et al [56] used dielectric barrier discharge surface pre-treatment on both glass and polyethylene film, before coating with either perflouroalkyltrichlorosilanes or the monchloro-substituted version of the same 
molecule. Changes in surface stoichiometry and roughness, similar to that seen in the present study, were reported. Most of the treatments, whilst showing large increases in hydrophobicity over the untreated substrates, do not reach levels of ultra-hydrophobicity. The exception is DPD and trichloro fluorosilane treated polyethylene, which shows water contact angle of $142.6^{\circ}$. No super-hydrophobic surfaces were, however, reported. Also of note, Jung et al [57] used a two-step process somewhat similar to that documented in the present study. Initially, a plasma vacuum was used to etch and expose imbedded particles, before a polyfluorinated silane, the exact molecule is not disclosed, was applied to increase the hydrophobicity of an undefined hard paint surface. The study used nanoparticles as the means of generating roughness, so not providing the larger range order of roughness reported in the present study. In the study by Jung et al, only modest increases in water contact angles were reported to occur, from $73^{\circ}$ to $\sim 102^{\circ}$ [57].

Importantly, the two-step process detailed in the present study offers a notable increase in hydrophobicity compared to that reported by the aforementioned researchers.

\section{Conclusions}

The aim of the present study was to modify an existing hydrophilic polyurethane paint coating to make it more hydrophobic. Such hydrophobicity can be beneficial in both automotive and marine applications where, for example, enhanced corrosion resistance or antifouling might be required. The approach taken was to use a twostage process combining an initial oxygen/argon plasma pretreatment followed by a fluoroalkyl silane coating.

The oxygen/argon plasma initially increased hydrophilicity of the polyurethane by the introduction of oxygen functionality. This allowed the fluoroalkyl silane solution to wet the modified PU effectively and possibly to enable the FAS to undergo condensation reactions to give a well-adhered and conformal coating. With extended plasma treatment times, multiscale surface texture was created by a preferential ablation mechanism removing the polyurethane phase but leaving the inorganic fillers relatively intact. 
The fluoroalkyl silane coating was shown to deposit conformally. When combined with the amplified roughness generated from the plasma pretreatment, the influence of the conformal fluoroalkyl silane coating was to reverse the effect of the plasma and instead generate optimised hydrophobicity on the final treated surface.

It has been shown that by combining the optimised oxygen/argon plasma pretreatment with a subsequently-applied fluoroalkyl silane final treatment, a superhydrophobic PU-based surface was generated, with water contact angles up to $153^{\circ}$ observed.

There is, however, a trade-off inherent in using increased surface roughness as a method of producing a superhydrophobic PU surface. The alteration, although vital to the achievement of highly anti wetting properties, has implications on the aesthetic considerations of the surface; specifically, reduced levels of specular reflection (gloss) are reported due to increases in scattered light and there is also an accompanying change in surface colouration. A decrease in gloss level and further discolouration were observed with increasing plasma exposure time.

\section{References:}

[1] D. K. Chattopadhyay and K. V. S. N. Raju, "Structural engineering of polyurethane coatings for high performance applications," Prog. Polym. Sci., vol. 32, no. 3, pp. 352-418, 2007.

[2] E. Delebecq, J. P. Pascault, B. Boutevin, and F. Ganachaud, "On the versatility of urethane/urea bonds: Reversibility, blocked isocyanate, and nonisocyanate polyurethane," Chem. Rev., vol. 113, no. 1, pp. 80-118, 2013.

[3] U. Poth, Automotive Coatings Formulations. Hannover: Vincentz Network $\mathrm{GmbH} \& \mathrm{Co}, 2008$.

[4] A. S. Rad, E. Binaeian, and A. Mirabi, "Automotive clear coat polyurethane (desmodur Z4470 + Different Desmophen) with respect to some physical and self-healing properties," Asian Journal of Chemistry, vol. 24, no. 3. pp. 13131315, 2012.

[5] H.-J. Streitberger and K.-F. Dössel, Eds., Automotive Paints and Coatings. Morlenbach: Wiley-VCH, 2008.

[6] D. Li, J. Zhao, H. GU, M. LU, F. Ding, and J. Hu, "Surface Modification of Medical Polurethane By Plasma Treatment," Chinese Phys. Lett., vol. 9, no. 2, pp. 79-82, 1993.

[7] F. D. Egitto and L. J. Matienzo, "Plasma modification of polymer surfaces for adhesion improvement," IBM J. Res. Dev., vol. 38, no. 4, pp. 423-439, 1994. 
[8] S. D. Seul, J. M. Lim, S. H. Ha, and Y. H. Kim, "Adhesion enhancement of polyurethane coated leather and polyurethane foam with plasma treatment," Korean J. Chem. Eng., vol. 22, no. 5, pp. 745-749, 2005.

[9] S. Yang, L. Wang, C. F. Wang, L. Chen, and S. Chen, "Superhydrophobic thermoplastic polyurethane films with transparent/ fluorescent performance," Langmuir, vol. 26, no. 23, pp. 18454-18458, 2010.

[10] P. Roach, N. J. Shirtcliffe, and M. I. Newton, "Progess in superhydrophobic surface development," Soft Matter, vol. 4, no. 2, p. 224, 2008.

[11] E. Lepore and N. Pugno, "Superhydrophobic Polystyrene by Direct Copy of a Lotus Leaf," Bionanoscience, vol. 1, no. 4, pp. 136-143, 2011.

[12] Z. Guo, W. Liu, and B. L. Su, "Superhydrophobic surfaces: From natural to biomimetic to functional," J. Colloid Interface Sci., vol. 353, no. 2, pp. 335-355, 2011.

[13] M. Liu, Y. Zheng, J. Zhai, and L. Jiang, "Bioinspired super-antiwetting interfaces with special liquid-solid adhesion," Acc. Chem. Res., vol. 43, no. 3, pp. 368-377, 2010.

[14] H. J. Ensikat, P. Ditsche-Kuru, C. Neinhuis, and W. Barthlott, "Superhydrophobicity in perfection: The outstanding properties of the lotus leaf," Beilstein J. Nanotechnol., vol. 2, no. 1, pp. 152-161, 2011.

[15] M. Callies and D. Quéré, "On water repellency," Soft Matter, vol. 1, no. 1, p. 55, 2005.

[16] R. N. Wenzel, "Resistance of solid surfaces to wetting by water.," J. Ind. Eng. Chem. (Washington, D. C.), vol. 28, pp. 988-994, 1936.

[17] B. D. Cassie, "Of porous surfaces," no. 5, pp. 546-551, 1944.

[18] J. Tsibouklis and T. G. Nevell, "Ultra-Low Surface Energy Polymers: The Molecular Design Requirements," Adv. Mater., vol. 15, no. 78, pp. 647-650, 2003.

[19] P. Peng, Q. Ke, G. Zhou, and T. Tang, "Fabrication of microcavity-array superhydrophobic surfaces using an improved template method," J. Colloid Interface Sci., vol. 395, no. 1, pp. 326-328, 2013.

[20] R. P. S. Chakradhar, V. D. Kumar, J. L. Rao, and B. J. Basu, "Fabrication of superhydrophobic surfaces based on ZnO-PDMS nanocomposite coatings and study of its wetting behaviour," Appl. Surf. Sci., vol. 257, no. 20, pp. 85698575, 2011.

[21] M. a Nilsson, R. J. Daniello, and J. P. Rothstein, "A novel and inexpensive technique for creating superhydrophobic surfaces using Teflon and sandpaper," J. Phys. D. Appl. Phys., vol. 43, no. 4, p. 045301, 2010.

[22] J. Zhang, J. Li, and Y. Han, "Superhydrophobic PTFE surfaces by extension," Macromol. Rapid Commun., vol. 25, no. 11, pp. 1105-1108, 2004.

[23] W. Wu, Q. Zhu, F. Qing, and C. C. Han, "Water repellency on a fluorinecontaining polyurethane surface: Toward understanding the surface selfcleaning effect," Langmuir, vol. 25, no. 1, pp. 17-20, 2009.

[24] F. Zheng, H. Deng, X. Zhao, X. Li, C. Yang, Y. Yang, and A. Zhang, "Fluorinated hyperbranched polyurethane electrospun nanofibrous membrane: 
Fluorine-enriching surface and superhydrophobic state with high adhesion to water," J. Colloid Interface Sci., vol. 421, pp. 49-55, 2014.

[25] D. Wu, W. Ming, R. van Benthem, and G. de With, "Superhydrophobic Fluorinated Polyurethane Films," J. Adhes. Sci. Technol., vol. 22, no. 15, pp. 1869-1881, 2008.

[26] W. O. Gordon, G. W. Peterson, and E. M. Durke, "Reduced Chemical Warfare Agent Sorption in Polyurethane-Painted Surfaces via Plasma-Enhanced Chemical Vapor Deposition of Perfluoroalkanes," ACS Appl. Mater. Interfaces, pp. 5-8, 2015.

[27] B. Qian and Z. Shen, "Fabrication of superhydrophobic surfaces by dislocation-selective chemical etching on aluminum, copper, and zinc substrates," Langmuir, vol. 21, no. 20, pp. 9007-9009, 2005.

[28] I. Bernagozzi, C. Antonini, F. Villa, and M. Marengo, "Fabricating superhydrophobic aluminum: An optimized one-step wet synthesis using fluoroalkyl silane," Colloids Surfaces A Physicochem. Eng. Asp., vol. 441, pp. 919-924, 2014.

[29] J.-D. Brassard, D. K. Sarkar, and J. Perron, "Fluorine Based

Superhydrophobic Coatings," Appl. Sci., vol. 2, no. 2, pp. 453-464, 2012.

[30] C. Su, J. Li, H. Geng, Q. Wang, and Q. Chen, "Fabrication of an optically transparent super-hydrophobic surface via embedding nano-silica," Appl. Surf. Sci., vol. 253, no. 5, pp. 2633-2636, 2006.

[31] N. Saleema, D. K. Sarkar, D. Gallant, R. W. Paynter, and X. G. Chen, "Chemical nature of superhydrophobic aluminum alloy surfaces produced via a one-step process using fluoroalkyl-silane in a base medium," ACS Appl. Mater. Interfaces, vol. 3, no. 12, pp. 4775-4781, 2011.

[32] M. Thieme, C. Blank, H. Worch, R. Frenzel, F. Simon, H. G. P. Lewis, and a J. White, "Superhydrophobic Aluminum Surfaces : Preparation Routes ," in Contact Angle, Wettability and Adhesion, vol. 6, L. Mittal, Kash, Ed. Boca Raton: CRC Press, 2009, pp. 251-267.

[33] K. Tsougeni, N. Vourdas, a. Tserepi, E. Gogolides, and C. Cardinaud, "Mechanisms of oxygen plasma nanotexturing of organic polymer surfaces: From stable super hydrophilic to super hydrophobic surfaces," Langmuir, vol. 25, no. 19, pp. 11748-11759, 2009.

[34] A. Pizzi and K. L. Mittal, Eds., Handbook of Adhesive Technology, Revised and Expanded, 2nd ed. CRC Press.

[35] J. J. Licari and D. W. Swanson, Adhesives Technology for Electronic Applications: Materials, Processing, Reliability, 2nd ed. Oxford: Elsevier, 2011.

[36] J. P. Youngblood and T. J. McCarthy, "Ultrahydrophobic polymer surfaces prepared by simultaneous ablation of polypropylene and sputtering of poly(tetrafluoroethylene) using radio frequency plasma," Am. Chem. Soc. Polym. Prepr. Div. Polym. Chem., vol. 40, no. 2, pp. 563-564, 1999.

[37] K. Teshima, H. Sugimura, Y. Inoue, O. Takai, and A. Takano, "Transparent ultra water-repellent poly(ethylene terephthalate) substrates fabricated by oxygen plasma treatment and subsequent hydrophobic coating," Appl. Surf. Sci., vol. 244, no. 1-4, pp. 619-622, 2005. 
[38] M. Morra, E. Occhiello, and F. Garbassi, "Contact angle hysteresis on oxygen plasma treated polypropylene surfaces," J. Colloid Interface Sci., vol. 132, no. 2, pp. 504-508, 1989.

[39] T. Murakami, S. Kuroda, and Z. Osawa, "Dynamics of Polymeric Solid Surfaces Treated with Oxygen Plasma: Effect of Aging Media after Plasma Treatment," J. Colloid Interface Sci., vol. 202, no. 1, pp. 37-44, 1998.

[40] A. Oláh, H. Hillborg, and G. J. Vancso, "Hydrophobic recovery of UV/ozone treated poly(dimethylsiloxane): Adhesion studies by contact mechanics and mechanism of surface modification," Appl. Surf. Sci., vol. 239, no. 3-4, pp. 410-423, 2005.

[41] V. Jokinen, P. Suvanto, and S. Franssila, "Oxygen and nitrogen plasma hydrophilization and hydrophobic recovery of polymers," Biomicrofluidics, vol. 6, no. 1, pp. 1-10, 2012.

[42] R. Jafari, S. Asadollahi, and M. Farzaneh, "Applications of Plasma Technology in Development of Superhydrophobic Surfaces," Plasma Chem. Plasma Process., vol. 33, no. 1, pp. 177-200, 2012.

[43] E. M. Liston, L. Martinu, and M. R. Wetheimer, "Plasma surface modification of polymers for improved adhesion: a critical review," J. Adhes. Sci. Technol., vol. 7, no. 10, 1993.

[44] J. Marquez-Velasco, M. E. Vlachopoulou, A. Tserepi, and E. Gogolides, "Stable superhydrophobic surfaces induced by dual-scale topography on SU8," Microelectron. Eng., vol. 87, no. 5-8, pp. 782-785, 2010.

[45] L. Chen, G. Henein, J. A. Liddle, and B. Drive, "Super-hydrophobic and / or Super-hydrophilic Surfaces Made by Plasma Process National Institute of Standards and Technology," Energy, vol. 3, pp. 3-6, 2009.

[46] B. Cortese, S. D’Amone, M. Manca, I. Viola, R. Cingolani, and G. Gigli, "Superhydrophobicity due to the hierarchical scale roughness of PDMS surfaces," Langmuir, vol. 24, no. 6, pp. 2712-2718, 2008.

[47] H. Muijiser, "Acute (4-hour) toxicity study with Dynasylan VPS 8815 in rats," Degussa, 2001. .

[48] D. K. Owens and R. C. Wendt, "Estimation of the surface free energy of polymers," J. Appl. Polym. Sci., vol. 13, no. 8, pp. 1741-1747, 1969.

[49] G. Ström, M. Fredriksson, and P. Stenius, "Contact angles, work of adhesion, and interfacial tensions at a dissolving Hydrocarbon surface," J. Colloid Interface Sci., vol. 119, no. 2, pp. 352-361, 1987.

[50] Y. X. Qiu, D. Klee, W. Plüster, B. Severich, and H. Höcker, "Surface modification of polyurethane by plasma-induced graft polymerization of poly(ethylene glycol) methacrylate," J. Appl. Polym. Sci., vol. 61, no. 13, pp. 2373-2382, 1996.

[51] D. Rosu, L. Rosu, and C. N. Cascaval, "IR-change and yellowing of polyurethane as a result of UV irradiation," Polym. Degrad. Stab., vol. 94, no. 4, pp. 591-596, 2009.

[52] ASTM International, "ASTM E284 - 13b: Standard Terminology of Appearance," 2013. [Online]. Available: http://www.astm.org/Standards/E284.htm. [Accessed: 15-May-2015]. 
[53] T. a Trezza and J. M. Krochta, "Heterogeneity of Biopolymer Coatings," J. Appl. Polym. Sci., vol. 79, no. 12, pp. 2221-2229, 2001.

[54] J. Pospíšil and S. Nešpurek, "Photostabilization of coatings. Mechanisms and performance," Prog. Polym. Sci., vol. 25, no. 9, pp. 1261-1335, 2000.

[55] M. L. Abel, R. D. Allington, R. P. Digby, N. Porritt, S. J. Shaw, and J. F. Watts, "Understanding the relationship between silane application conditions, bond durability and locus of failure," Int. J. Adhes. Adhes., vol. 26, no. 1-2, pp. 2-15, 2006.

[56] L. J. Ward, J. P. S. Badyal, a. J. Goodwin, and P. J. Merlin, "Solventless coupling of perfluoroalkylchlorosilanes to atmospheric plasma activated polymer surfaces," Polymer (Guildf)., vol. 46, no. 12, pp. 3986-3991, 2005.

[57] S. Jung and S. Seidl, "Hydrophobing hard paint surfaces," DE102014003922 B3; WO 2015 139824-A1, 24-Sep-2015. 